\title{
Corrientes ideológicas al interior del movimiento estudiantil sinaloense, México (1965-1970)*
}

\section{Resumen}

El presente artículo analiza las diferentes corrientes ideológicas al interior del movimiento estudiantil sinaloense de 1965 a 1970. Para ello, se recurrió metodológicamente a dos generaciones, la primera denominada generación adulta era de izquierda y progresista, quienes disfrutaban de círculos literarios y ocupaban cargos dentro del gobierno estatal y de la Universidad. La segunda, generación joven integrado por estudiantes universitarios nacieron en la etapa de estabilidad económica, quienes frecuentaban los círculos de discusión intelectual creado por los normalistas y universitarios. Ambas generaciones abrazaron el proyecto democratizador de Carlos A. Madrazo, que predominó en la Universidad Autónoma de Sinaloa (UAS) desde 1966 hasta 1968, momento cuando la izquierda ascendió a la dirección de la Federación de Estudiantes Universitarios de Sinaloa (FEUS), que implementó una intensa pedagogía cultural a través de los festivales culturales.

\section{Palabras clave}

Tesauro: Movimiento estudiantil, universidades, ideología, democratización.

Referencia bibliográfica para citar este artículo: Santos Cenobio, Rafael. "Corrientes ideológicas al interior del movimiento estudiantil sinaloense, México (1965-1970)". Anuario de Historia Regional y de las Fronteras 26.2 (2021): 359-399.

Fecha de recepción: 6/12/2020

Fecha de aceptación: 22/11/2020

Rafael Santos Cenobio: Doctor en Ciencias Sociales. Profesor de asignatura de la Universidad Autónoma de Sinaloa. Mención honorífica en el Premio del Ensayo Histórico, Social y Cultural Sinaloa 2013 Miembro del Sistema Nacional de Investigadores (SIN), nivel I. Código ORCID: 0000-0003-3831-418X. Correo electrónico: rafaelsantos921@gmail.com.

\footnotetext{
* Este trabajo es un apartado de la tesis de Maestría en Historia de México, que lleva como título: "Los enfermos": un movimiento político-armado en Sinaloa (1972-1976).
} 


\title{
Ideological Currents Within the Sinaloan Student Movement, Mexico (1965-1970)
}

\begin{abstract}
This article analyzes the different ideological trends within the Sinaloan student movement from 1965 to 1970. For this purpose, two generations were used methodologically, the first so-called adult generation which was left-wing and progressive, and enjoyed literary circles and held positions within the state and university government. The second, young generation made up of university students were born in the stage of economic stability, who frequented the circles of intellectual discussion created by normal-school and university students. Both generations embraced the democratizing project of Carlos A. Madrazo, which prevailed at the Autonomous University of Sinaloa (UAS) from 1966 to 1968 when the left rose to the leadership of the Federation of University Students of Sinaloa (FEUS), which implemented an intense cultural pedagogy through cultural festivals.
\end{abstract}

\section{Keywords}

Thesaurus: Student Movement, Universities, Ideology, Democratization.

\section{Correntes ideológicas dentro do movimento estudantil Sinaloan, México (1965-1970)}

\section{Resumo}

Este artigo analisa as diferentes correntes ideológicas dentro do movimento estudantil de Sinaloense de 1965 a 1970. Para isso, duas gerações foram utilizadas metodologicamente, a primeira geração dita adulta era esquerdista e progressista, que gostava de círculos literários e ocupava cargos dentro do governo estadual e a Universidade. A segunda geração, formada por estudantes universitários, nasceu em estágio de estabilidade econômica, que frequentava os círculos de discussão intelectual criados pelos normalistas e universitários. Ambas as gerações abraçaram o projeto democratizante de Carlos A. Madrazo, que prevaleceu na Universidade Autônoma de Sinaloa (UAS) de 1966 a 1968, quando a esquerda ascendeu à liderança da Federação de Estudantes Universitários de Sinaloa (FEUS), que implantou uma pedagogia cultural intensa por meio de festivais culturais.

\section{Palavras chave}

Thesaurus: Movimento estudantil, universidades, ideologia, democratização. 


\section{Introducción}

Este artículo estudia las diferentes corrientes ideológicas al interior del movimiento estudiantil sinaloense, a través del método de generación, que implicó analizar la generación que nació durante los inicios de la formación del Estado mexicano, quienes disfrutaron de la estabilidad económica y política, además, se movieron dentro de los canales institucionales, hasta 1965 cuando abrazaron las ideas de democracia de Carlos Madrazo. Mientras que la generación que nació durante la etapa de bonanza económica, su primera experiencia política fue el movimiento cívico encabezado por Enrique Peña Batiz, quien pregonaba la democratización del Partido Revolucionario Institucional (PRI).

La producción sobre los movimientos estudiantiles en México y América Latina es muy basta, se ha escrito desde diferentes miradas. La mayoría de los trabajos han sido analizados desde la movilización de recursos, ${ }^{1}$ genero, ${ }^{2}$ análisis de marcos, ${ }^{3}$ historia y la memoria, ${ }^{4}$ arte y movilización estudiantil, ${ }^{5}$ las etapas del movimiento, ${ }^{6}$ campo intelectual, ${ }^{7}$ y la izquierda y los movimientos estudiantiles. ${ }^{8}$

\footnotetext{
${ }^{1}$ Denisse de Jesús Cejudo Ramos, "La Universidad en el naufragio: contienda política en la Universidad de Sonora, 1991" (Tesis, Doctorado en Historia Moderna y Contemporánea, Instituto de Investigaciones Dr. José María Luis Mora, 2016).

2 Gloria A. Tirado Villegas y Elva Rivera Gómez, "A cuarenta años del movimiento estudiantil. Universitarias de los años setenta en la Universidad Autónoma de Puebla, México", Cuadernos Intercambio sobre Centroamérica y el Caribe 1 (2014): 27-44; Gloria Armida Tirado Villegas, "Puebla 1961, género y movimiento estudiantil", La ventana 39 (2014): 179-207.

${ }^{3}$ Cuitláhuac Alfonso Galaviz Miranda, "Las dimensión simbólica de la protesta: el caso de las movilizaciones estudiantiles de 1970-1973 en la Universidad de Sonora” (Tesis, Maestría en sociología política, Instituto de Investigaciones Dr. José María Luis Mora, 2016); Beatriz Galaviz Hernández, "En primavera florecen los murales'. El arte activista en el movimiento estudiantil de la Universidad de Sonora, 1991-1992. Prácticas y estrategias" (Tesis, Maestría en Ciencias Sociales, Universidad de Sonora, 2016).

${ }^{4}$ Juan Pablo Paredes, Nicolás Ortiz Ruiz y Camila Araya Guzmán, “Conflicto social y subjetividad política: performance, milicias y memoria en la movilización estudiantil post 2011", Persona y sociedad 2 (2018): 122-149; Alejandro Fielbaun S., "Memoria, patrimonio y pos dictadura", Oralidad y memoria 1 (2009): 6-71; Jorge Mendoza García, Marcos sociales, artefactos e historia (Universidad Pedagógica Nacional, México, 2015); Marco A. Braghetto G., "1968 en México: la inesperada significación de un movimiento estudiantil de intención democrática-popular”, Escrita 2 (2019): 46-71.
}

${ }^{5}$ Álvaro Acevedo Tarazona, Andrés David Correa Lugos y Yuly Andrea Mejía Jerez, "Cultura, política y revolución en las universidades colombianas: el arte como vanguardia del cambio social a partir de 1968”, Escrita 2 (2019): 24-44.

${ }^{6}$ Yllich Escamilla Santiago, "El movimiento estudiantil de Huanta, un eco andino del 68", Escrita 2 (2019): 102-116; Kevyn Simón Delgado, “El 'parteaguas' a nivel local. El movimiento del 68 en la Universidad Autónoma de Querétaro”, Escrita 2 (2019): 195-216.

${ }^{7}$ Diego Andrés Quintero Timaná y Juan Pablo Rosero Gomajoa, "La configuración del campo intelectual contestatario: Universidad de Nariño (1960-1970)", Anuario de Historia Regional y de las Fronteras, 2 (2020), 187-217.

8 Kevyn Simón Delgado, "El Partido Comunista Mexicano y el movimiento estudiantil de 1968: enfrentamiento, aportación e impacto" (Tesis, Licenciatura en Historia, Universidad Autónoma de Querétaro, 2013); J. Rodrigo Moreno Elizondo, "El movimiento estudiantil-popular de 1968 y la recomposición de las organizaciones políticas de izquierda", Revista Mexicana de Ciencias Politicas y Sociales 234 (2018): 239264); María Guadalupe Moreno González, "La izquierda y los movimientos sociales: el caso del Partido Comunista en Jalisco y la guerra sucia en Guadalajara de los años setenta", R.H.A 142 (2010): 9-23. 
Este trabajo trata de observar a dos generaciones, una adulta y la otra joven que confluyeron en el grupo Francisco I. Madero, cuyo proyecto fue lograr la democratización del PRI en Sinaloa, sin embargo fue derrotado por el gobernador Leopoldo Sánchez Celis. En la generación adulta estaban viejos profesores comunistas, maestros de corte progresista, catedráticos afines al marxismo; mientras que en la generación juvenil destacaban estudiantes de secundaria, preparatoria y de nivel superior, especialmente de la carrera de Derecho, Economía y Agricultura. El proyecto democratizador del grupo Francisco I. Madero inicio en 1965, con el movimiento político encabezado por Enrique Peña Batiz "El Gallo de Oro" y se extendió a la Universidad - con las ideas de democratizar el gobierno universitario, reformar los programas de estudios, construir un partido político de oposición al PRI y sumarse a las luchas populares- hasta 1968, momento cuando la Juventud Comunista de México (JCM), filial del Partido Comunista de México (PCM), comenzó a organizarse e imprimió su propio cariz al movimiento, le apostó por la formación política del estudiantado por medio de festivales culturales, que incluía poesía, música de protesta, conferencias, proyección de documentales y distribución de material, sobre todo procedente de Vietnam, China y Cuba.

Para estudiar las corrientes políticas al interior del movimiento estudiantil, fue necesario recurrir a la bibliografía existente, así como archivos locales y nacionales, aunado a entrevistas con actores que participaron en el movimiento estudiantil. La investigación desarrollada tiene que ver con las diferentes localidades urbanizadas, como Los Mochis, Mazatlán, pero sobre todo con su epicentro en Culiacán. En ese sentido, el artículo se inscribe dentro de la Historia regional, que se entiende como lo micro, donde emergían las historias que le habían conformado y constituido y donde surgía una identidad sociohistórica que en muchos de los casos no coincidía con las versiones nacionales y oficiales, incluso en la conformación de una periodización que respondiera a la forma en que la sociedad se había manifestado en la historia provincial o local. ${ }^{9}$

\section{Un marco contextual de la Universidad}

Durante la década de 1960 y 1970, se implementó un proceso de reforma de los sistemas educativos en Europa y América Latina. Esta reforma fue producto de la consolidación del Estado de Bienestar en Europa y el crecimiento económico acaecidos en los países latinoamericanos. Esto arrojó como resultado la universalización de la educación de nivel medio, lo cual generó mayor demanda de acceso a la educación superior. ${ }^{10}$

Los estudiantes universitarios latinoamericanos durante largo tiempo tuvieron un papel protagónico en el ámbito de las cuestiones educativas, políticas y sociales. ${ }^{11}$ Durante varios años los estudiantes (de Venezuela y Brasil) disfrutaron de la

\footnotetext{
${ }_{9}^{9}$ Pablo Serrano Álvarez, “Tendencias y enfoques metodológicos, 1968-1990”, Relaciones 72 (1997): 52.

${ }^{10}$ Claudio Suasnábar, "Los ciclos de reforma educativa en América Latina: 1960, 1990 y 2000, Revista española de educación comparada 30 (2017): 117-118.

${ }^{11}$ En 1918, los estudiantes de Argentina plantearon como demandas la autonomía universitaria, participación en la administración de la Universidad, asistencia optativa, abolición de restricciones religiosas, ayuda
} 
autonomía y cogobierno, pero entre 1964 y 1966, tales privilegios fueron trastocados en muchos de los casos por el ascenso de gobiernos militares en América Latina, que por medio de la imposición de autoridades buscaron someter a las universidades. ${ }^{12}$

En 1966, en el Cuarto Congreso Estudiantil Latinoamericano, realizado en La Habana, se creó la Organización Continental de Estudiantes Latinoamericanos, que proponía desarrollar una lucha contra el imperialismo y desarrollar los vínculos con los campesinos y obreros. Los estallidos estudiantiles se presentaron en diferentes países latinoamericanos: $:^{13}$ en 1964 los estudiantes participaron en la caída del régimen en Ecuador y Bolivia; en 1966 hubo agitaciones estudiantiles en México, Ecuador, Colombia, Brasil (protesta contra la dictadura militar) y Venezuela (el apoyo a las guerrillas y la agitación permanente llevaron al gobierno a ocupar la Universidad de Caracas el 4 de diciembre). ${ }^{14}$ Estos movimientos explotaron en un contexto donde los modelos de industrialización y la caída de los precios de los productos primarios, marcaron un nuevo escenario caracterizado por las crisis fiscales y de las balanzas de pagos, y la incapacidad de los gobiernos para mantener los niveles de financiamiento que requería la educación superior públicas para cubrir nuevas demandas sociales. ${ }^{15}$

Para el caso de México, en 1960 contaba con 34.6 millones de habitantes, de los cuales 5.76 millones se encontraba matriculados en el sistema educativo, de esa suma sólo 75 mil estudiantes ${ }^{16}$ pertenecía al nivel superior. Existían una difícil transición entre la primaria a la secundaria y el nivel superior, por ejemplo, de cada 23 alumnos de primaria uno llegaba a la secundaria; mientras que a nivel superior se calculaba uno por cada 66 alumnos de primaria. Esa desproporción decreció para 1970, en educación superior (sumó 200 mil estudiantes) de un alumno por cada 43 de primaria. ${ }^{17}$ El origen social de los estudiantes que accedían a la educación superior provenían de los sectores medios, quienes "habían crecido con el desarrollo del

económica a estudiantes, orientación social de la universidad y un sistema democrático de organización universitaria. Esas exigencias en años posteriores se expandieron a otras universidades latinoamericanas como el Perú (1919), Chile (1920), Colombia (1924), Paraguay (1927), México en (1929), Brasil y Bolivia en 1928.Fred Halliday "Estudiantes del mundo, uníos" en Poder estudiantil. Problemas, diagnóstico y acción, (Coords.) Cockburn Alexander y Robin Blackburn (Caracas: Editorial Nuestro Tiempo, 1970), 353-354.

${ }^{12}$ Mauricio Archiva, "Entre la academia y la política: el movimiento estudiantil en Colombia, 1920-1974” en Movimientos estudiantiles en la historia de América Latina, coord. Renate Marsiske (México: Universidad Nacional autónoma de México, Centro de Estudios sobre la Universidad y Plaza Valdés, 1999) 166-127.

${ }^{13}$ Entre las demandas de las movilizaciones destacaban autonomía, cogobierno, exigencia de mayores presupuestos, cambios curriculares, mayor cobertura en educación superior, por la masificación de las masas de bachilleres.

${ }^{14}$ Jean Meyer, "El movimiento estudiantil en América Latina”, Sociológica año 23, 68 (2008): 180-181.

${ }^{15}$ Claudio Rama Vitale, "La tercera reforma de la educación superior en América Latina y el Caribe: masificación, regulaciones e internacionalización”, Educación y pedagogía 28, 46 (2006): 14-5.

${ }^{16}$ Roberto Rodríguez Gómez, "Evolución reciente de la matrícula universitaria. Datos y reflexiones", Escenario para universidad contemporánea, coordinadores, Humberto Muñoz García y Roberto Rodríguez Gómez (México: Universidad Autónoma de México, 1995) 33.

${ }^{17}$ Mario Guillermo González Rubí, "La educación superior en los sesenta: los atisbos de una transformación sin retorno", Sociológica 23, 68 (2008): 18-19. 
país y que por mejores condiciones de existencia superaban la selectividad social que se realizaba a lo largo del sistema escolar, reuniendo los requisito escolares para demandar escolaridad superior y buscaban mayor movilidad y consolidación de una nueva posición". ${ }^{18}$

En 1960, el sistema educativo público contaba con 21 universidad públicas estatales siete institutos regionales, la Universidad Autónoma de México (UNAM) y el Instituto Politécnico Nacional. Mientras que 19 instituciones pertenecían al ámbito privado. Para 1970, el número de instituciones públicas se duplicó, sólo cuatro estados no contaban con universidad y el número de instituciones privadas ascendió a $34 .{ }^{19} \mathrm{Al}$ final de la década de 1960, la UNAN recogía más de la mitad de la matricula nacional, mientras que las universidades del interior de la República mexicana daban atención a la demanda regional. ${ }^{20}$

En cuanto a la Universidad de Sinaloa (US), ${ }^{21}$ en 1965 cambió a Universidad Autónoma de Sinaloa (UAS), ${ }^{22}$ en el ciclo escolar 1962-1963, la matrícula se distribuía como sigue: Secundaria Diurna y Nocturna, 2 551; Preparatoria Diurna y Nocturna, 643; Ciencias Químico-Biológicas, 47; Economía, 52; Ciencias Físico-Matemáticas, 73; Contabilidad y Administración, 139; Derecho y Ciencias Sociales, 177; Superior de Agricultura, 148. El total de la matricula era 3841 alumnos. ${ }^{23}$ Aunque hay que aclarar que no aparecía incluida la matrícula de las carreras subprofesionales como Enfermería y Obstetricia, Taller de Artes Plásticas y Academia de Danza, que en el ciclo escolar 1959-1960, tenía 11, 40 y 55 alumnos respectivamente.

\footnotetext{
${ }^{18}$ María de Ibarra, La educación superior en México (Caracas: Centro Regional para la Educación Superior en América Latina y el Caribe, 1986) 42.

${ }^{19}$ Mario Guillermo González Rubí, "La educación superior en los sesenta: los atisbos de una transformación sin retorno", 24.

${ }^{20}$ Roberto Rodríguez Gómez, "Evolución reciente de la matrícula universitaria. Datos y reflexiones", 34-35.

${ }^{21}$ El 9 de octubre de1941, la Universidad Socialista del Noroeste, cambió a Universidad de Sinaloa. Para 1945 la Universidad contaba con las escuelas Secundaria, Preparatoria, Normal, Enfermería y Obstetricia; facultades de Ciencias Químico-Biológicas, Ciencias Matemáticas, Enseñanza Comercial y Técnica, Derecho y Ciencias Sociales, Estudios Agrícolas; e institutos de Estudios Médicos, Investigaciones Económicas-Sociales e Investigaciones Históricas. Durante el lapso que duró la US el Consejo Universitario funcionaba como máxima autoridad, integrado por el rector, el secretario general, los directores de escuelas y facultades, un profesor, un alumno y el presidente de la Federación de Estudiantes Universitarios (FEUS). Marco Antonio Berrelleza Fonseca y Dina Beltrán López, "De Liceo Rosales a Universidad Autónoma de Sinaloa (1872-1972)", La educación superior en el proceso histórico de México. Semblanzas de instituciones, tomo IV, coord. David Piñera Ramírez (México: Secretaría de Educación Púbica, Universidad Autónoma de Baja California y Asociación Nacional de Universidades e Instituciones de Educación Superior, 2002), 181.

${ }^{22}$ En diciembre de 1965, el gobernador Leopoldo Sánchez Celis decretó la autonomía de la Universidad. El máximo órgano de gobierno de la institución fue la Junta de Gobierno, encargada de nombrar y remover al rector y a los directores de las facultades, escuelas e institutos. La segunda autoridad fue el Consejo Universitario, presidido por el rector como presidente.

${ }^{23}$ Dina Beltrán López, “La educación en Sinaloa en la etapa posrevolucionaria, 1945-1980. Segunda parte. La educación superior: la Universidad Autónoma de Sinaloa y otras instituciones", Historia temática de Sinaloa. Educación y política educativa, Coordinadores Miguel Ángel Rosales Medrano, Dina Beltrán López y Jorge Luis Sánchez Gastélum (México: Gobierno del Estado de Sinaloa, Instituto Sinaloense de Cultura y Consejo Nacional para la Cultura y las Artes), 210.
} 
Sin embargo, la Universidad incrementó su matrícula de manera exponencial en el periodo de 1965 a 1969. En el ciclo 1966-1967 en el nivel profesional existían 1420 alumnos: 127 en Química, 320 en Contabilidad y Administración, 277 en Derecho, 88 en Economía, 157 en Físico- Matemáticas, 451 en Agricultura. En el nivel sub-profesional se ubicaba Enfermería (93) y Trabajo Social (52). El nivel preparatoria superaba la profesional alcanzando 1882 alumnos; el grueso de la matrícula se concentraba en Culiacán con 1383 estudiantes. Para ese tiempo también figuraban el Centro de Estudios de Idiomas (228), Centro de Estudios Musicales (27) y Taller de Artes Plásticas (39). ${ }^{24}$

En el ciclo escolar 1967-1968 con respecto al anterior, aumentó 434 estudiantes en el nivel profesional, las escuelas que más crecieron fueron Química (70), Contabilidad y Administración (117), Agricultura (157); mientras que FísicoMatemáticas (42) superó a Economía, que tuvo seis alumnos menos. La preparatoria sumó 486 estudiantes, de los cuales la capital sinaloense agregó la mayoría (332). Las carreras especiales aumentaron 252. En total la Universidad tenía 5039 alumnos. Para el ciclo 1968-1969 aumentó 416 la población estudiantil.

La matrícula estudiantil se expandió fuertemente en el periodo de 1965 a 1970. Un factor fue que parte de la población joven del ámbito rural sinaloense comenzó a desplazarse a la ciudad, muchas de las veces era para ingresar a la preparatoria y a la carrera profesional universitaria, especialmente en Culiacán y luego en Mazatlán. El fenómeno de la emigración en la entidad permitió a los principales centros urbanos concentrar población, por ejemplo, el municipio de Culiacán en 1960 poseía 55 256 habitantes, para 1970 su población subió a 360 412; en cambio Mazatlán en 1960 contaba con 112619 personas y para 1970 su población era de $167616 .{ }^{25} \mathrm{Un}$ segundo factor fue que la Universidad recibió un numeroso grupo de mujeres que se concentraban especialmente en las carreras de Enfermería y Trabajo social. Un tercer factor fue que la UAS incorporó varias escuelas preparatorias en Escuinapa, Guasave, Guamúchil, así como la Rafael Buelna Tenorio, Nocturna Cervantes, Popular Emiliano Zapata y Popular Nocturna Número 1 en Culiacán.

En fin, el movimiento estudiantil que inició en 1966 puso en su agenda la fundación e incorporación de las escuelas preparatorias, al mismo tiempo gestionó la creación de la casa estudiantil Rafael Buelna Tenorio (1968), donde residieron los jóvenes provenientes del ámbito rural.

Durante la etapa de la US, la FEUS organizaba eventos como Día del estudiante y del Maestro, ${ }^{26}$ así como las elecciones de reinas, novatadas y auspiciaba las campañas estudiantiles a favor de los candidatos del Partido Revolucionario

\footnotetext{
${ }^{24}$ Dina Beltrán López, "La educación en Sinaloa en la etapa posrevolucionaria, 1945-1980, 218.

${ }^{25}$ Gustavo Lozano Velásquez, Entre la claridad y la bruma de la educación superior en Sinaloa, (México: Universidad Autónoma de Sinaloa, 1988) 34.

${ }^{26}$ Anónimo, Estatutos Generales y Reglamentos de Festejos de la Federación de Estudiantes Universitarios de Sinaloa (Culiacán: Universidad de Sinaloa, 1950) 3.
} 
Institucional (PRI). ${ }^{27}$ En ese sentido la FEUS se convirtió en un trampolín para saltar a los puestos políticos del gobierno del estado. Esas prácticas predominaron hasta principios de la década de los sesenta, dejando de un lado, las preocupaciones de la reforma universitaria y cuestiones sociales. ${ }^{28}$

En 1966, los estudiantes de las escuelas y facultades de la UAS se organizaron bajo el Directorio Estudiantil de Huelga (DEH), ${ }^{29}$ presidido por el estudiante de Economía, Fausto Burgueño Lomelí. Esa organización logró la renuncia del rector Julio Ibarra Urrea, asimismo tomó el control de la FEUS, que fue dirigido por el estudiante de Derecho Anacleto Terrazas Araujo. ${ }^{30}$ En adelante la FEUS se convirtió en columna vertebral del activismo político universitario: en 1967, organizó el Primer Consejo Nacional Ordinario de la Central Nacional de Estudiantes Democráticos (CNED), donde se decidió luchar por la liberación de los presos político en México, para presionar al gobierno se llevó a cabo la Marcha por la Ruta de la Libertad. ${ }^{31}$

El 68 mexicano se expresó en Sinaloa a través del Consejo Estudiantil Estatal de Huelga (CEEH), ${ }^{32}$ replicando el Consejo Nacional de Huelga órgano rector del movimiento estudiantil captalino. El CEEH desplegó por la geografía sinaloense brigadas que se dedicaban a efectuar mítines relámpagos, con el fin de propagandizar, difundir una noticia, una denuncia, un problema e informar al pueblo de la situación de represión y persecución que el gobierno realizaba en contra del estudiantado. ${ }^{33}$ Además de su solidaridad con el movimiento capitalino, los estudiantes sinaloenses insistían en sus demandas particulares como la aprobación de la nueva Ley Orgánica la UAS. ${ }^{34}$ Los actores principales de la movilización eran Jesús Michel Jacobo, presidente de la FEUS; Fausto Burgueño y Ceceña Cervantes, alumno y director de la Escuela de Economía; y el Lic. Rafael Guerra Miguel, presidente de la Sociedad General Maestros Catedráticos Universitario. ${ }^{35}$

\footnotetext{
${ }^{27}$ Liberato Terán Olguín, Nueva universidad (México: Universidad Autónoma de Sinaloa, 1984) 52.

${ }^{28}$ Diario de Culiacán, 11 de junio de 1966.

${ }^{29}$ Diario de Culiacán, 20 de septiembre de 1966.

${ }^{30}$ Archivo Histórico de la Universidad Autónoma de Sinaloa (AHUAS). Fondo Documentación de Sesión Extraordinaria del Consejo Universitario, f. 173.

${ }^{31}$ Lorenzo Q. Terán, Tribuna impresa. Crónica periodística, 1966-1970 (México: Universidad Autónoma de Sinaloa, 2004) 22-80.

${ }^{32}$ Lo constituían la FEUS, la Federación de Estudiantes Normalistas de Sinaloa (FENS); la Federación de Estudiantes Secundarianos del Estado de Sinaloa (FESES); y miembros de las sociedades de alumnos del Tecnológico de Culiacán. Las comisiones en las que se dividía CEEH eran: Finanzas, Prensa y Propaganda, Asuntos Jurídicos, Información y Brigadas. En la base del Consejo aparecían los comités de lucha por escuela y facultades.

${ }^{33}$ Rafael Santos Cenobio, El movimiento estudiantil en la UAS (1966-1972) (México: Universidad Autónoma de Sinaloa, 2005) 181.

${ }^{34}$ Rafael Santos Cenobio, El movimiento estudiantil en la UAS, 86-87.

${ }^{35}$ Director Federal de Seguridad, Fernando Gutiérrez Barrios", México, 6 de septiembre de 1968 en AGN, México, Fondo DFS, Caja 100-23-1, Versiones Publicas de la UAS, legajo, 5/16, 6 de septiembre de 1968, f. 136.
} 
Para 1969, bajo la presidencia de Liberato Terán, la FEUS impulsó el primer Congreso de los estudiantes universitarios de Sinaloa. En ese evento se llevó a cabo un balance las experiencias y logros del movimiento estudiantil. Además, se planteó como resolutivo resolver la crisis educativa, mediante la reforma de las leyes, reglamentos, programas, planes y métodos que regulen la enseñanza en la UAS; unificar a todos los estudiantes mexicanos, para garantizar el avance y el triunfo de la lucha estudiantil nacional; recoger las tradiciones revolucionarias del pueblo y de los estudiantes mexicanos; democratizar los órganos de gobierno del estado y del país y solidarizarse con la lucha del pueblo; repudiar el colonialismo y neocolonialismo y apoyar la lucha de los pueblos por su liberación. ${ }^{36}$ Un elemento destacable fue que el Comité Ejecutivo de la FEUS se transformó en Consejo Estudiantil.

Para 1970, la Junta de gobierno en contraposición con la opinión del estudiantado impuso como rector al Lic. Gonzalo Armienta Calderón. Lo cual provocó una huelga generalizada de las escuelas y facultades que arreciaron las manifestaciones públicas, hasta que lograron la renuncia del rector en 1972.

\section{El proyecto hegemónico y su cuestionamiento}

Después la destitución del Dr. Julio Ibarra como rector de la UAS, la generación adulta se posesionó del poder al interior de la Universidad. La generación joven también se apoderó de la dirección de la FEUS, especialmente el sector progresista de la Escuela de Derecho permaneció hasta 1968, momento cuando ascendió a la dirección gente de la JCM.

El proyecto democrático construido por la generación joven y adulta tuvo una serie de implicaciones. Los progresistas se acercaban más a la idea de democracia como comunidades armónicas en la que los individuos vivan plenamente, no al servicio de otros individuos e instituciones, sino en la libertad de ejercer sus libertades creativas para vidas plenas no a costa de otros individuos o interfiriendo en comunidades que no son las suyas. Mientras que los comunistas imaginaban la democracia donde los seres humanos no se explotan unos a los otros, donde unos no sacan ventaja de los otros donde los unos no expropian a los otros. ${ }^{37}$

La generación joven seguía entusiasmada en protestar en contra del PRI por "la absurda imposición a diputado federal estatal, por sus sucios procedimientos antidemocráticos, para elegir candidatos a diputados federales". ${ }^{38}$ Para contrarrestar la práctica antidemocrática, los universitarios proponían lanzar una candidatura independiente ${ }^{39}$ de "dos o tres auténticos universitarios destacados por su actuación

\footnotetext{
${ }^{36}$ AHUAS, Fondo Alfredo Millán, f. 3.

${ }^{37}$ Walter D. Mignolo, "Democracia liberal, camino de la autoridad humana y transición al vivir bien", Sociedad e Estado 29, 1 (2014): 28.

${ }^{38}$ Archivo General de la Nación (AGN), México, Fondo Dirección Federal de Seguridad (DFS), Versiones públicas de la Universidad Autónoma de Sinaloa (UAS), Caja 100-23, legajo 1, f. 39.

${ }^{39}$ Entre los posibles candidatos aparecían: el Lic. José Luis Ceceña, Fausto Burgueño Lomelí, Rodolfo Rodríguez Meléndrez, Liberato Terán, Cesar García Morgan, Salvador Quintero Lozano, Odín Hildebrando
} 
entre el alumnado, elementos de reconocida filiación de izquierda radical" ${ }^{40}$ Los comunistas y progresistas incluían dentro de su proyecto político formar un partido político de oposición al PRI, esto en aras de crear un Movimiento Nacional Revolucionario apegado a los principios planteados por Carlos A. Madrazo. En ese sentido, en Los Mochis, la Asociación Estudiantil de la preparatoria promovió reuniones para tomar partido en las elecciones federales en los cuatro distritos electores de Sinaloa. ${ }^{41}$

Lo que quería la generación joven era la pluralidad de partidos políticos donde pudieran participar los obreros y campesinos en las elecciones nacionales y locales. ${ }^{42}$ El proyecto de Madracista siguió vigente hasta 1968, que incluso los estudiantes de la Escuela de Derecho y Ciencias Sociales deseaban que Madrazo fungiera como padrino de generación.

La generación joven igualmente se volcó a democratizar la Escuela Secundaria Revolución Incorporada a la Dirección General de Educación en el Estado, donde estalló una huelga respaldado por 284 alumnos, quienes pedían la renuncia del director de la Escuela el Prof. Carlos López Portillo, por irregularidades ${ }^{43}$ cometidas en la escuela.

En el movimiento huelguísticos participaron los cuadros dirigentes de la FEUS como su vicepresidente Rito Terán Olguín, quien afirmaba "que su agrupación les ofrecía apoyo moral en virtud de que habían constatado que su movimiento era justo, pues tanto alumnos como padres de familia eran explotados por el director, quien al mismo tiempo explotaban a los maestros pagándoles solo $\$ 15$ pesos la hora". ${ }^{4}$ Otros estudiantes y universitarios protagonistas en la huelga fueron Guadalupe Meza Mendoza, presidente de la Sociedad de Alumnos de la Escuela de Economía; Russell González de la Escuela de Agricultura; así como Eduardo Aispuro Beltrán de la Sociedad de Alumnos de la Escuela Secundaria Federal No. 2, quienes señalaban que su participación fue en representación del Ateneo Universitario Sinaloense (grupo de teoría marxista-leninista), dirigido por Rodolfo Rodríguez Meléndrez "El Chichi" ${ }^{45}$ Los estudiantes consiguieron la renuncia del director, la creación de la Sociedad de Padres de Familia y de la Sociedad de Alumnos. ${ }^{46}$

\footnotetext{
Ibarra Cervantes, Andrés Cañas Martínez y Anacleto Terrazas Araujo.

${ }^{40}$ AGN, México, Fondo DFS, Versiones públicas de la UAS, Caja 100-23, legajo 1, f. 430.

${ }^{41}$ AGN, México, Fondo DFS, Versiones públicas de la UAS, Caja 100-23, legajo 1, f. 454.

${ }^{42}$ AGN, México, Fondo DFS, Versiones públicas de la UAS, Caja 100-23, legajo1, f. 432.

${ }^{43}$ El profesor se le acusaba de aprovecharse del personal, porque cobraba sesenta pesos por inscripción y cincuenta pesos por colegiatura a los alumnos. Además, al director se le imputaba de no promover la impartición de las materias adecuadas para ingresar a las escuelas superiores; asimismo, no estaban de acuerdo en que los grupos de alumnos se integraran de 98 alumnos por cada uno y que no existían mesa bancos para para que los estudiantes se sentaran.

${ }^{44}$ AGN, México, Fondo DFS, Versiones públicas de la UAS, Caja 100-23, legajo 1, f. 33.

${ }^{45}$ AGN, México, Fondo DFS, Versiones públicas de la UAS, Caja 100-23, legajo 1, f. 43.

${ }^{46}$ AGN, México, Fondo DFS, Versiones públicas de la UAS, Caja 100-23, legajo 1, f. 30.
} 
Los cuadros dirigentes de la FEUS, proyectaron su mirada hacia el exterior, se sumaron a la Confederación Nacional de Estudiantes Democráticos (CNED), ${ }^{47}$ organización que promovió varias actividades como las siguientes: encuentro nacional de dirigentes estudiantiles donde se trataron asuntos relacionados con la autonomía universitaria y la democratización de la enseñanza universitaria; ${ }^{48}$ se organizó la marcha por la Ruta de la Libertad, que inició el 3 de febrero en Dolores Hidalgo y culminó en Morelia, Michoacán, para exigir la libertad de los presos políticos - como Rafael Aguilar Talamantes y Enrique Cabrera, dirigentes de la CNED $;{ }^{49}$ y se protestó contra el imperialismo yanqui por intervención en Vietnam y otros países. ${ }^{50}$ La CNED fue cuestionada al interior de la UAS por la Confederación de Jóvenes Mexicanos (CJM), ${ }^{51}$ al afirmar que "la CJM es la auténtica central representativa del estudiantado nacional, ya que la CNED es un grupo minoritario". ${ }^{52}$

Pero el eje principal del proyecto fue "lograr la autonomía verdadera, con base en reformas y hacen un llamado a los estudiantes, catedráticos, obreros y campesinos y al pueblo de Culiacán, para que unidos como un solo hombre luchen por la defensa de la Universidad". ${ }^{53}$ La autonomía universitaria fue uno de los puntos más complicados para los estudiantes, pues fue un proyecto de largo plazo que implicó batallas, enfrentamientos y manifestaciones públicas violentas contra el cacicazgo político encabezado por Leopoldo Sánchez Celis, quien había fungido, como senador, gobernador (1963-1968) y presidente nacional del PRI.

El ejercicio de la autonomía universitaria se defendía en diferentes universidades del país, en la Universidad Autónoma de México (UNAM), los alumnos de la Escuela Nacional de Economía se manifestaban por la elección de consejeros técnicos y universitarios bajo el régimen de voto universal y directo buscando la paridad en dichos consejos. En La Universidad Autónoma de Puebla

\footnotetext{
${ }^{47}$ La CNED surgió en 1962, pero se configuró en 1963, con el estallido del movimiento estudiantil, que fue el primer intento de integrar una organización nacional, democrática e independiente del aparato oficial y del partido oficial. La fuerza mayoritaria provenía del PCM, así que para 1966 la política sectaria de la mayoría de la dirección de la organización en un ala estudiantil de la Juventud Comunista. Antonio Gómez Nashiki, "El movimiento estudiantil mexicano. Crónica de las organizaciones y tendencias políticas, 1910-1971", La educación superior en el proceso histórico de México, t. II, Coord. David Piñera Ramírez (México: Siglo XIX, 2001) 320.

${ }^{48}$ AGN, México, Fondo DFS, Versiones públicas de la UAS, Caja 100-23, legajo 1, f. 164.

${ }^{49}$ AGN, México, Fondo DFS, Versiones públicas de la UAS, Caja 100-23, legajo 1, f. 155.

${ }^{50}$ AGN, México, Fondo DFS, Versiones públicas de la UAS, Caja 100-23, legajo 1, f. 159.

${ }^{51}$ La CJM nació en 1938, como sector juvenil del Partido de la Revolución Mexicana. En los ataques a la educación superior popular y nacionalista, desde 1956, empezaron a agudizarse cada vez más, y en ese embate la CJM mantuvo una actitud pasiva. La CJM era en ese momento la organización estudiantil que aglutinaba a la mayor parte de las federaciones estudiantiles de la Republica. Estaba afiliadas a ella la Federación de Estudiantes de las Normales Rurales, la Federación de Estudiantes Técnicos, la Federación de Estudiantes de Agricultura y las federaciones estudiantiles de Coahuila, Nuevo León, Distrito Federal, Yucatán, Jalisco, Michoacán y Guanajuato. En 1962, en el VIII Congreso de la CJM celebrado en Guadalajara, se definieron dos corrientes, uno oficialista y la otra que buscaba la independencia y la democracia en el movimiento estudiantil. Antonio Gómez Nashiki, 307- 308.
}

${ }^{52}$ AGN, México, Fondo DFS, Versiones públicas de la UAS, Caja 100-23, legajo 1, f. 352.

${ }^{53}$ AGN, México, Fondo DFS, Versiones públicas de la UAS, Caja 100-23, legajo 1, f. 164. 
(AUP), los estudiantes comunistas se pronunciaron por la cogestión y facilidades a obreros y campesinos a ingresar a la Universidad. ${ }^{54}$ Mientras que en la Universidad Michoacana de San Nicolás de Hidalgo, desde 1961 la Federación de Estudiantes de la Universidad Michoacana (FEUM) y el Consejo Estudiantil Nicolaíta (CEN) (ambas organizaciones de izquierda incluían militantes de la JCM y un sector del profesorado con pasiones progresistas) lograron llevar a la rectoría de la Universidad a Eli de Gortari. Sin embargo, el proyecto de la democratización del gobierno universitario ${ }^{55}$ no se resolvió rápidamente, ya que fue una de las banderas de las luchas estudiantiles en Michoacán. ${ }^{56}$

Otro punto del proyecto de los universitarios sinaloenses, en sentido social fue protestar por el alza inmoderada de los víveres de primera necesidad.$^{57}$ Los cuadros dirigentes de la FEUS alzaron la voz contra el gobierno del estado, Sánchez Celis, al acusarlos de procurar el bienestar de una élite que se había enriquecido a costa de la explotación de las masas populares. Como remedio para solucionar el problema, los universitarios proponían que las secretarías de Industria y Comercio y de Agricultura y Ganadería deberían nombrar inspectores para fiscalizar la producción de la leche y proponer medidas para que bajen el precio de los productos básicos. ${ }^{58}$

El proyecto hegemónico inspirado en Madrazo, especialmente del Grupo Francisco I. Madero, se fue nutriendo de otras experiencias de maestros y estudiantes de la izquierda marxista tanto de Sinaloa como de otras latitudes del país. Los puntos torales fueron la democratización del gobierno universitario, que implicaba elegir al rector por medio del Consejo Universitario, paridad en los Consejos Técnicos y Universitario tanto de maestros como de estudiantes; reforma a los planes de estudio; y formar un partido de oposición al PRI donde participaran estudiantes o profesionistas de ideología izquierdista o progresista. De 1966 a 1968, la cuestión social se limitó a la creación de una casa del estudiante para albergar a los hijos de los obreros y campesinos provenientes del ámbito rural.

De 1966 a 1968, el ambiente político y cultural que se vivía en la Universidad tenía estrecha relación con la Revolución Cubana, ya que los estudiantes escuchaban grabaciones en discos o en casetes de los discursos de Fidel Castro o bien la información llegaba a través de la radio de onda corta. Al respecto uno de los activistas rememora:

\footnotetext{
${ }^{54}$ Enrique de la Garza, León Tomas Ejea y Luis Fernando Macías, El otro movimiento estudiantil (México: Extemporáneos México, 1986) 226-229.

${ }^{55}$ Desaparición de la Junta de Gobierno, Elección del rector por el Consejo Universitario, paridad en los Consejos Técnicos y Consejo universitario, tanto de profesores como alumnos.

${ }^{56}$ Ángel Chávez Mancilla, "De la Nicolaíta al 68. Eli de Gortari y la protesta universitaria", Signos Históricos XIX, 37 (2017): 133 y 134.

${ }^{57}$ AGN, México, Fondo DFS, Versiones públicas de la UAS, Caja 100-23, legajo 1, f. 425.

${ }^{58}$ AGN, México, Fondo DFS, Versiones públicas de la UAS, Caja 100-23. legajo 1, fs. 433-434.
} 
A veces llegaban aquí a la Universidad discos o grabaciones que alguien los traía y se ponían en tocadiscos y era una multitud que se reunía alrededor de ellos. También había compañeros que de manera personal, que tenía acceso a la lectura, películas o grabaciones. Se sabían por ejemplo discursos. ${ }^{59}$

Asimismo surgió entre el estudiantado universitario afinidad ideológica con el guerrillero guatemalteco Luís Turcio Lima (Hebert), ${ }^{60}$ quien en 1962 junto con el teniente Marco Antonio Yon Sosa (El Chino) encabezaron la guerrilla Frente Alejandro de León Aragón Movimiento 13 de Noviembre (MR13). ${ }^{61}$ Siguiendo al guerrillero guatemalteco, los estudiantes de la Escuela de Agricultura y Economía -cuestionando el proyecto hegemónico- formaron el grupo Turcio Lima, quienes proponían como forma de lucha el foco guerrillero. ${ }^{62}$

Otro grupo contrahegemónico fue el Frente Estudiantil Revolucionario (FER), que era dirigido por estudiantes de la Escuela Superior de Agricultura como Alfredo Octavio Millán Alarid, Wilfrido Fierro Báez, Russell González Zumárraga "El Yuca", así como los alumnos de Economía José de Jesús Montiel Montoya y Horacio Lozano. Ese grupo pertenecía a la La Liga Comunista Espartaco, que pregonaba como ideología el maoísmo.

Russell González Zumárraga, en los documentos de la Dirección Federal de Seguridad, aparece como procedente del estado de Yucatán y que ingresó a la Escuela de Agricultura alrededor de 1966. González Zumárraga comenzó a resaltar a partir de mayo de 1967, momentos cuando junto con Rito Terán Olguín encabezaron una comisión que se trasladó a la Escuela de Agricultura Hermanos Escobar de Ciudad Juárez, Chihuahua, con fin de conocer el problema y posteriormente lo den a conocer a los estudiantes sinaloenses". ${ }^{63}$ A finales de 1967, González Zumárraga participó en el movimiento de la escuela Secundaria Revolución que pedía la destitución de su director. ${ }^{64}$ En ese mismo año, el dirigente estudiantil junto con Wilfrido Báez y Millán Alarid encabezaron una huelga en la Escuela de Agricultura, con el fin de pedir la construcción de un edificio para su plantel, "ya que no desean seguir compartiendo las aulas, laboratorio con los preparatorianos". ${ }^{65}$

\footnotetext{
${ }^{59}$ Entrevista de Rafael Santos Cenobio a Liberato Terán Olguín, Culiacán, Sinaloa, 15 de julio de 2004.

${ }^{60}$ Proponía la guerra en Guatemala bajo un proceso de ofensiva constante, desarrollado en sentido geográfico, partiendo de un punto y extendiéndose a nuevas zonas regiones y sectores sociales y convertirse en una guerra nacional y generalizada. Sólo el desarrollo de la guerra podría hacer que la ciudad se incorpore a ella; así el movimiento sería de la ciudad al campo y luego del campo a la ciudad y el campesinado sería la base de la fuerza principal de la revolución y la guerra revolucionaria. La población indígena sería la protagonista esencial en la guerra revolucionaria. Carlos Figueroa Ibarra, "Partido, poder, masas y revolución (la izquierda en Guatemala, 1954-1996)", Cuadernos de Marte 1 (2010): 50.

${ }^{61}$ Juan Carlos Vázquez Mendeles, “El olvido en la memoria de Rogelia Cruz Martínez”, Tzintzun 56 (2012): 173 .

${ }^{62}$ Ronaldo González Valdés, Izquierda y Universidad: un discurso rampante (1966-1985) (México: Colección Editorial Aldea 21 y Serie Sociedad y Pensamiento 1, 2016) 52.

${ }^{63}$ AGN, México, Fondo DFS, Versiones públicas de la UAS, Caja 100-23, legajo 1, f. 140.

${ }^{64}$ AGN, México, Fondo DFS, Versiones públicas de la UAS, Caja 100-23, legajo 1, f. 43.

${ }^{65}$ AGN, México, Fondo DFS, Versiones públicas de la UAS, Caja 100-23, legajo 1, f. 44.
} 
En 1968, González Zumárraga realizó una serie de actividades: en la escuela de la Colonia 6 de Enero organizó un mitin donde criticó a las autoridades federales y estatales y, elogió a los "candidatos del PPS, sin mencionar nombre, quienes vienen facilitando el equipo de sonido que utiliza en estos actos y crítico al del PRI y PAN, acusándolos de reaccionarios y paleros del gobierno"; 66 al tiempo que exaltó el valor de líder el grupo Francisco I. Madero, Enrique Peña Batiz, porque fue el único que se atrevió a desafiar el gobernador Leopoldo Sánchez Celis; destacó como activista del FER; participó en el Consejo Estudiantil Estatal de Huelga (CEEH); fue orador en el Congreso del Estado en defensa de la Ley Orgánica propuesta por el Consejo Universitario de la UAS. En diciembre de 1968, González Zumárraga fue detenido por la Policía Judicial, para luego ser expulsado del estado de Sinaloa. ${ }^{67}$

Millán Alarid apareció en la escena política universitaria a partir de 1968, bajo el paraguas del FER. El dirigente estudiantil formó parte del $\mathrm{CEEH}$, aunque hay que aclarar que durante su trayectoria como estudiante no ostentó puesto alguno en la dirección de su escuela o en la misma FEUS, esto seguramente porque lo consideraba "pequeño burgués". Millán se le observaba participando como orador y agitador político en diferentes mítines y manifestaciones públicas. Por ejemplo, el 7 de octubre de 1968 llevó a cabo con González Zumárraga y Wilfrido Fierro un mitin donde "refirieron al movimiento estudiantil y exhortaron al pueblo a unirse al mismo; asimismo tocaron el punto del subsidio congelado para la Universidad". ${ }^{68}$ Para diciembre de 1968, Millán Alarid fue detenido por la Policía Judicial del estado junto con González Zumárraga, José Cabada Rubio y José Manuel Ochavarría. ${ }^{69}$

Wilfrido Fierro Báez, fungió como presidente de la Sociedad de Alumnos de la Escuela de Agricultura durante el periodo, 1967-1968. ${ }^{70}$ Fierro Báez en 1967 encabezó el Comité del Consejo de Huelga en la misma escuela que pedía la construcción de su propio plantel con sus respectivas aulas, ya que no "desean seguir compartiendo el que ocupa la Escuela preparatoria de la Universidad." 71

En la escuela de Economía miembros del FER eran Lozano Santillán y Montiel Montoya. El primero en 1966, formó parte del Comité Central de Huelga contra el rector Julio Ibarra Urrea; al mismo tiempo comulgaba con las ideas del grupo Francisco I. Madero. ${ }^{72}$ Lozano Santillán protagonizó varios mítines y manifestaciones públicas, por ejemplo, en enero de 1967, destacó como orador donde proponía para bajar los precios de los productos agrícolas (hortalizas y cártamo) era necesario que el gobierno bajara las tasas impositivas. ${ }^{73}$ El mencionado dirigente seguía muy de cerca el movimiento

\footnotetext{
${ }^{66}$ AGN, México, Fondo DFS, Versiones Publicas de la UAS, Caja 100-23-1, legajo, 2/16, f. 265.

${ }^{67}$ AGN, México, Fondo DFS, Versiones Publicas de la UAS, Caja 100-23-1, legajo, 2/16, f. 392.

${ }^{68}$ AGN, México, Fondo DFS, Versiones Publicas de la UAS, Caja 100-23-1, legajo 2/16, f. 294.

${ }^{69}$ AGN, México, Fondo DFS, Versiones Publicas de la UAS, Caja 100-23-1, legajo 2/16, f. 392.

${ }^{70}$ Rafael Santos Cenobio, 218.

${ }^{71}$ AGN, México, Fondo DFS, Versiones públicas de la UAS, Caja 100-23, legajo 1, f. 48-49.

${ }^{72}$ AGN, México, Fondo DFS, Versiones públicas de la UAS, Caja 100-23, legajo 1, f. 430.

${ }^{73}$ AGN, México, Fondo DFS, Versiones Publicas de la UAS, Caja 100-23-1, legajo, 2/16, f. 370.
} 
guerrillero acaecidos en la ciudad de Madera, ${ }^{74}$ Chihuahua, así como la movilización coprera $^{75}$ en Acapulco, Guerrero. Mientras que Montiel Montoya fue reclutado a partir de 1968, momento cuando participó como orador y militante del FER.

Los postulados de la Liga Comunista Espartaco descansaban sobre el maoísmo, ${ }^{76}$ según Millán Alarid, uno de sus principales protagonistas, ese movimiento planteaba una crítica contra el "improvicionismo soviético [...] criticaba casi todas las directivas políticas que hacía el partido comunista maoísta, los criticaba como revisionistas. ${ }^{77}$ En ese sentido, para los espartacos, la reforma universitaria era una lucha "pequeño burguesa"; para ellos había que hacer trabajo político en el campesinado y en las capas pobres. El reclutamiento de sus cuadros lo hicieron a través de la fundación de la preparatoria Popular Nocturna y de la casa del estudiante Sinaloense. ${ }^{78}$

Los espartacos inspirados en el maoísmo llevaron a cabo una serie de acciones. A principios de 1968, un grupo de estudiantes encabezados por Montiel Montoya, Fierro Báez, Daniel Zapata Díaz y González Zumárraga trataron de obstaculizar la sesión del Consejo Universitario, pero fueron sometidos por los dirigentes de la FEUS, Fausto Burgueño, Jesús Michel Jacobo presidente del organismo estudiantil. ${ }^{79}$ Los militantes del FER en algunos volantes acusaban a los dirigentes estudiantiles de la FEUS y al Lic. Rafael Guerra Miguel de "deshonestos y oportunistas". ${ }^{80}$ En el edificio central de la UAS, los maoístas rindieron homenaje al Che Guevara, elogiaron sus actividades guerrilleras, leyeron poemas y pasajes alusivas a su vida; al mismo

\footnotetext{
${ }^{74}$ El 23 de septiembre de 1965, un grupo de jóvenes del Grupo Popular Guerrillero (GPG), armados con rifles, carabinas, escopetas y bombas caseras intentaron asaltar el Cuartel de Ciudad Madera. El resultado fue la muerte de ocho de los combatientes: Arturo y Emilio Gamiz, Oscar Sandoval, Rafael Martínez, Salomón Gaytán, Antonio Scobell, Miguel Quiñones y Pablo Gómez; cinco lograron escapar: Ramón Mendoza, Juan José Fernández, Guadalupe Scobell, Francisco Ornelas y Florencio Lugo Hernández. Carmen Andrea Elena Ríos, "Ni mártires ni bandidos. La guerrilla del GPC en Chihuahua (1963-1965", Debates por la historia 6, 1 (2018): 65.

${ }^{75}$ En Acapulco, el 20 de agosto de 1967, los líderes de la Unión Regional de Productores de Copra del Estado de Guerrero, apoyados por gatilleros de renombre y con el apoyo del gobernador Raymundo Abarca Alarcón, abrieron fuego y reprimieron a 800 productores de copra, cuando intentaban ingresar al edificio de dicha sede, donde se llevaría a cabo un congreso y se manifestaban contra la elección de Jesús Guerrero como presidente de esa organización. Raúl Sendic García Estrada, "La masacre de la Coprera", La Jornada (Acapulco), 20 de julio de 2018: 1.

${ }^{76}$ En el norte de México la izquierda mexicana de 1968 y 1988 abrazaron el maoísmo, que buscaba salir de los cauces institucionales y hacer política popular. Para eso tenía que generar formar organizativas independientes con elementos de democracia directa (asambleas) y apelar a la movilización de los colonos, campesinos y estudiantes como medio de solución de los problemas económicos. La idea era que los activistas se fusionaran con el pueblo y de esta convivencia se politizara a la población para que el pueblo mismo resolviera sus necesidades. Jorge Iván Puma Crespo, "Los maoístas del norte de México: breve historia de Política Popular-Línea Proletaria, 1969-1979”, Revista izquierdas 27 (2016): 203.

${ }^{77}$ Entrevista de Rafael Santos Cenobio a Alfredo Octavio Millán Alarid, Culiacán, Sinaloa, 15 de julio de 2007.

${ }^{78}$ Entrevista a Terán Olguín.

${ }^{79}$ AGN, México, Fondo DFS, Versiones Publicas de la UAS, Caja 100-23-1, legajo, 2/16, f. 311.

${ }^{80}$ AGN, México, Fondo DFS, Fondo DFS, Versiones Publicas de la UAS, Caja 100-23-1, legajo, 2/16, f. 290.
} 
tiempo, criticaron al gobierno federal y estatal por quitar el subsidio de la UAS. ${ }^{81}$ Por último, en un mitin en el edificio central, los espartacos con un aparato de sonido se pronunciaron contra "la suspensión del movimiento de huelga del profesorado acusándolos de traidores" 82

En 1971 su aislamiento del movimiento de masas los llevó a entrar en un proceso de declive; e incluso algunos miembros del FER, sobre todo, de Economía se inclinaron por la oficialidad al grado de pedir como padrino de generación al Secretario Presidencial Hugo Cervantes del Río. Mientras que, otros tantos (Agricultura) continuaron en la lucha estudiantil y con el surgimiento del "movimiento enfermo", se sumaron a él, entre los más representativos figuró Octavio Millán Alarid.

\section{El Grupo Francisco I. Madero: entre la democracia y la reforma universitaria}

En este apartado se estudiará la generación adulta y joven que participó en el grupo Francisco I. Madero. La generación social se entiende como el agregado de todas las personas nacidas en un lapso de veinte años, o en torno a la duración de una fase histórica (niñez y juventud) que comparten creencias, comportamientos y sentimientos comunes. ${ }^{83}$ Asimismo, la generación implica un nosotros (nuestra, somos, nos pertenece), que se siente por el solo hecho de haber sido testigos de los mismos procesos históricos teniendo una misma edad. Además, el tiempo histórico es el medio donde cada individuo absorbe los recuerdos que van quedando en su memoria. Así se forma la conciencia, por los sucesivos y permanentes cruces entre el tiempo histórico y el estado de desarrollo biopsíquico de cada individuo.

De ahí se entiende la permanente asociación entre generaciones y edad. ${ }^{84}$ Los procesos históricos llegan de manera distinta a cada espacio, las vivencias del día a día y los recuerdos que van quedando en la memoria de los sujetos que los habitan generan formas de conciencia posibles que son diferentes. El punto es que las distintas situaciones que describe una generación pueden dar origen a distintos modos de interpretar su particular posición en el proceso histórico. Cada una de estas interpretaciones constituye una unidad de generación, una particular lectura y actitud frente a la situación que vive la generación como conjunto abstracto, como generación real. ${ }^{85}$ La postura teórica de la generación bien se aplica al caso, ya que bajo el proyecto democrático participaron comunistas y sectores progresistas. La generación de la bonanza económica, más menos nacieron entre en 1946 y 1948, pues en 1966 tendría entre 17 y 20 años aproximadamente. Pero junto a ellos, estaba la generación adulta, quienes nacieron entre 1922, 1931, 1937, por ejemplo, Marco Cesar García

\footnotetext{
${ }^{81}$ AGN, México, Fondo DFS, Versiones Publicas de la UAS, Caja 100-23-1, legajo, 2/16, fs. 302-303.

${ }^{82}$ AGN, México, Fondo DFS, Versiones Publicas de la UAS, Caja 100-23-1, legajo, 2/16, f. 238.

${ }^{83}$ Manuela Caballero Guisado y Artemio Baigorri Agoiz, “¿Es operativo el concepto de generación?”, Aposta 56 (2013): 29.

${ }^{84}$ Felipe Ghiardo, “Generaciones y juventud: una relectura desde Mannheim y Ortega y Gasset", Última década 20 (2004): 32.

${ }^{85}$ Ghiardo, 33.
} 
Salcido rondaba en los 35 años; José Luis Ceceña Cervantes tenía 29 años; mientras que Rodolfo Monjaraz Buelna y Enrique Peña Batiz 49 y 44 años respectivamente.

La generación adulta, sobre todo Monjaraz Buelna y Ceceña Cervantes que militaban en la izquierda comunista y marxista, se movieron dentro de los canales institucionales, pues disfrutaron de puestos dentro del gobierno y de la Universidad, lo mismo que García Salcido, mientras que Peña Batiz participó en el deporte, el ocio y la iniciativa privada.

Para la generación adulta, el espacio de experiencia era más grande, pero su expectativa se acortaba; mientras que para los jóvenes como su espacio de experiencia era más corto, su horizonte de expectativa era de mayor alcance. Para la generación adulta, antes del movimiento democrático de 1965 y de la huelga estudiantil de 1966, ocuparon diferentes puestos en el gobierno; posteriormente, los profesores universitarios entre ellos Monjaraz Buelna fue rector de 1966 a 1970; mientras que Ceceña Cervantes ocupó el puesto de director de Economía en esos mismos años; y García Salcido fue Secretario General de la UAS. Los jóvenes apuntaron su mirada muy alto, democratizar la Universidad y la sociedad.

En ese sentido, Koselleck afirma que la experiencia es un pasado presente, cuyos acontecimientos han sido incorporados y pueden ser recordados. En la experiencia se fusionan tanto la elaboración racional como los modos inconscientes del comportamiento que no deben, o no debieran ya, estar presentes en el saber. Además, en la propia experiencia de cada uno, trasmitida por generaciones o instituciones, siempre está contenida y conservada una experiencia ajena. Mientras que el horizonte de experiencia está ligado a personas, siendo a la vez impersonal y es el futuro hecho presente; también incluye la esperanza, el temor, el deseo y la voluntad, la inquietud, pero también el análisis racional, así como la visión receptiva y la curiosidad. ${ }^{86}$

La generación joven nació durante la bonanza económica que experimentó el país, pero en la primera década de 1960 comenzaron acumular algunas experiencias, el autoritarismo del Estado mexicano, pero también se les presentó la oportunidad de sumarse a un movimiento de democratizador al interior del PRI y, unos meses después desarrollaron un movimiento estudiantil, que los hizo proyectar un futuro esperanzador, donde se lograse la democratización de la Universidad, de los sindicatos y del sistema político mexicano.

En 1938, el presidente Lázaro Cárdenas convirtió el Partido de la Revolución Mexicana (PRM), en una organización corporativa, al integrar los sectores obrero, popular, militar y campesino. ${ }^{87}$ Desde entonces, el PRM, luego PRI, se definió como brazo del Estado y, con el tiempo se convirtió en una casilla de registro en la que

\footnotetext{
${ }^{86}$ Reinhart Koselleck, Futuro pasado. Para una semántica de los tiempos históricos (España: Ediciones Paidós, 1993) 339-340.

${ }^{87}$ Miguel Ángel Ramírez Hernández, "La ideología y la institucionalización de la identidad política. El caso del Partido Revolucionario Institucional (1929-2017)" (Tesis, Maestría en Asuntos Políticos y Políticas Públicas, El Colegio de San Luis, 2018) 76.
} 
llegaba el político para obtener un puesto de representación. El partido al agrupar los sectores más importantes de la sociedad, se convertía en la correa de transmisión de sus inquietudes y, al llevar a los puestos de elección popular al hombre de uno de esos sectores, hacía posible que atendiera las demandas y problemas de la población. ${ }^{88}$

Aunque ninguna fuerza le disputaba la primacía al PRI, comenzaba a causar cansancio, por su capacidad para atraerse las fuerzas emergentes. Bajo ese contexto, Carlos A. Madrazo, ocupó la presidencia del PRI de diciembre de 1964 a noviembre de 1965. Madrazo se encontró con los siguientes problemas en el partido: los acarreos; no escuchar y no resolver los problemas de la gente; postular en las elecciones a personas cuyo único mérito era la amistad o el interés y no la creencia en los principios del partido; la influencia de los gobernadores en la elección de los candidatos a puestos de elección popular y en la construcción de las directivas locales del PRI.

Para refrescar el ambiente en el partido, Madrazo designó delegados en siete $\operatorname{estados}^{89} \mathrm{y}$, luego renovó los comités directivos estatales y municipales (mediante votación en asambleas) en nueve estados. ${ }^{90}$ Asimismo, el dirigente nacional se abocó a elegir los dirigentes seccionales por medio de asambleas, al tiempo que organizó elecciones en forma libre y espontánea para elegir candidatos a presidente municipales, síndicos y regidores. Otra reforma fue ordenar a los directivos estatales levantar nuevos padrones de afiliados desde las secciones electorales. Un último punto, fue la dotación de tierras y crédito, agilizar juicios, censar los centros de población, deslindar ejidos, parcelarios, darles asistencia técnica y proveerlos de agua. ${ }^{91}$

El líder nacional trató de democratizar al partido a partir del plano municipal para permitir la participación de individuos y grupos en el plano local y, romper con las prácticas de los gobernadores y caciques y, los dirigentes de los sectores del PRI. Para eso, ordenó indagar la cantidad real de los militantes, al tiempo que promovía la afiliación y re afiliación, así como la elección de los candidatos a puestos municipales. Esas acciones toparon con los cacicazgos regionales de los gobernadores.

En Sinaloa, por ejemplo, en septiembre de 1965, se realizaron elecciones internas para nominar candidatos del PRI a presidentes municipales y regidores. ${ }^{92}$ Sin embargo, en Culiacán, en las votaciones internas se enfrentaron, el ahijado político de Sánchez Celis, Alejandro Barrantes contra Enrique Higuera López, resultando triunfador el primero con 19340 votos, mientras que el perdedor obtuvo 15, 208.

\footnotetext{
${ }^{88}$ Rogelio Hernández Rodríguez, La formación del politico mexicano. El caso de Carlos A. Madrazo (México: El Colegio de México y la Universidad Autónoma de Tabasco, 1991) 129.

${ }^{89}$ Miguel Osorio Marbán (en Morelos), Heliodoro Hernández Loza (en Michoacán), Carlos Sansores Pérez (en Chihuahua) y Carlos Loret de Mola (en Durango). Su tarea era analizar la situación política de cada entidad para que el CEN pudiera renovar los comités estatales.

${ }^{90}$ Baja California, Chihuahua, San Luis Potosí, Guanajuato, Michoacán, Morelos, Durango, México y Puebla.

${ }^{91}$ Rogelio Hernández, 126-149.

${ }^{92}$ En los municipios de Ahome, Angostura, Badiraguato, Cosalá, Concordia, Choix, El Fuerte, Elota, Escuinapa, Guasave, Mazatlán, Mocorito, Salvador Alvarado, San Ignacio y Sinaloa de Leyva, y declara candidatos a los miembros del partido que lograron la mayoría de votos emitidos.
} 
Ambos intercambiaron acusaciones de fraude electoral. Así que intervino el CEN nacional del PRI, que decidió anular las elecciones y convocar nuevas para el 17 de octubre donde no podía participar ni Barrante ni Higuera. ${ }^{93}$ Pero Sánchez Celis no reconoció la decisión del CEN nacional, para él el triunfador era Barrantes. ${ }^{94} \mathrm{Al}$ anularse las candidaturas, en Culiacán la elección institucional transcurrió en medio de una tormenta; Alejandro Barrantes ${ }^{95}$ se presentó como candidato independiente al PRI, mientras que Alberto Zazueta era postulado por el Partido Francisco I. Madero, que era capitaneado por Enrique Peña Batiz "El Gallo de Oro". ${ }^{96}$ Nuevamente se reafirmó a Barrantes como ganador y luego fue declarado presidente municipal de Culiacán.

Ante los resultados, los seguidores del grupo Francisco I. Madero se echaron a las calles, una de sus primeras acciones fue constituir guardias permanentes en lugares públicos. Conforme pasaba el tiempo las protestas aumentaban, al grado de concentrar en los mítines hasta 10 mil personas. Pero pronto, Sánchez Celis desprestigió e intimidó a los dirigentes del movimiento, hasta girar ordenes de aprehensión en contra de Enrique Peña Batiz y Alberto Zazueta Duarte; mientras que los profesores universitarios Marco Cesar García Salcido y Tomás Rochín fueron exiliados. Esto provocó que para septiembre de 1966, las movilizaciones llegaran a su fin. ${ }^{97}$

El movimiento cívico fue derrotado, sin embargo, muchos los actores involucrados (maestros y estudiantes) llevaron las ideas de democracia a la UAS, lugar donde en 1966 lograron la caída del rector Julio Ibarra Urrea; y unos meses después, los estudiantes movilizados en asambleas generales eligieron a la directiva de la Federación de Estudiantes Universitarios Sinaloenses (FEUS); asimismo plantearon como reforma universitaria: paridad en el Consejo Universitario y en los consejos técnicos de cada una de las escuelas tanto de representación estudiantil como de docentes; desaparición de la Junta de Gobierno y creación de casas del estudiante. ${ }^{98}$ Los actores y el proyecto del grupo Francisco I. Madero mantuvo su hegemonía hasta 1968, momento cuando comenzó a tener fuerza el Partido Comunista Mexicano (PCM), a través de la Juventud Comunista.

\footnotetext{
${ }_{93}^{93}$ Pedro Castro, "Carlos A. Madrazo y la reforma imposible del PRI", Polis 3.1 (2007): 170-80.

${ }^{94}$ Ricardo Pozas-Horcasitas, "La democracia fallida: la batalla de Carlos A. Madrazo por cambiar al PRI", Revista Mexicana de Sociología 70.1 (2008): 70.

${ }^{95}$ El candidato del gobernador era arropado por la alta sociedad de Culiacán: empresarios, agricultores, burócratas, funcionarios, sindicatos de maestros, todos aglutinados en organismos como la Confederación de Trabajadores de México (CTM), Confederación de Asociaciones Agrícolas del Estado de Sinaloa (CAADES), Asociación de Agricultores del Río Culiacán (AARC) y la (CNOP), entre otras organizaciones corporativas.

${ }^{96}$ Este grupo estuvo apoyado por gente ordinaria de Culiacán, algunos universitarios, maestros, pequeños comerciantes y varios profesionistas.

${ }^{97}$ Rafael Santos Cenobio, El Movimiento estudiantil en la UAS (1966-1972), 52.

${ }^{98}$ Liberato Terán Olguín, Sinaloa: estudiantes en lucha (México: Universidad Autónoma de Sinaloa, 1982) 132-133; Rafael Santos Cenobio, 87.
} 
En las filas del grupo Francisco I. Madero destacó todo un abanico de actores como universitarios, campesinos y obreros. La cabeza visible era Enrique Peña Batiz, ${ }^{99}$ quien había fungido como profesor de inglés en una escuela privada, presidente juvenil en el Distrito Federal de los Partidos del Pueblo y coordinador de campaña presidencial del general Miguel Henríquez Guzmán, ${ }^{100}$ como resultado fue recluido preso en Lecumberri, compartiendo celda con Fidel Castro. ${ }^{101}$ Enrique Ruiz de Alba era empleado de la Telégrafos nacionales y dueño del pasquín El Costeño. Mientras que Pedro Oropeza era profesor de la escuela primaria Antonio Rosales de la misma capital sinaloense, quien afirmaba que "Sánchez Celis está a punto de caer del poder y ridiculizó el programa Sinaloa en Marcha". ${ }^{102}$ Anatolio Ortega Ortega, dirigente de los estudiantes de secundaria del estado, quien se destacó por haber participado en la quema de cines en Culiacán. ${ }^{103}$ Otros de los estudiantes de secundaria era José Quiroz Torres, quien atacó al gobernador Sánchez Celis y su hijo Leopoldo Sánchez Duarte. ${ }^{104}$

Un sector importante dentro del grupo Francisco I. Madero, fueron los profesores y estudiantes universitarios. Uno de ellos fue el Lic. y notario público Marco César García Salcido, ${ }^{105}$ quien estudió derecho en la Facultad de Derecho y Ciencias

\footnotetext{
${ }^{99}$ Peña Batiz, nació el 9 de abril de 1922 en Culiacán, fue el cuarto hijo de siete del matrimonio formado por el Ing. Enrique Peña Alcalde, quien fue vicerrector del Colegio Civil Rosales y de la química Veneranda Batiz Paredes. Sus estudios de primaria los realizó en Culiacán y a los 13 años curso la secundaria y preparatoria en el en el St. Catherine's Military School en Anaheim y en el Vilanova University en Ojai, California, UASA. Regresó a Culiacán donde se desempeñó como profesor de inglés de la Pre vocacional. En 1950, creó junto con otros médicos los Laboratorios Farmacéuticos Medicina Tropical Laveran; en 1958, participa en la actividad productiva del rancho Los Cascabeles dedicado a la agricultura y a la ganadería. De 1979 a 1981 se desempeñó como diputado de la alianza Asociación Política "Francisco I. Madero y el Partido Auténtico de la Revolución Mexicana.

${ }^{100}$ Viejos cardenistas, desplazados por los dos gobiernos posteriores a Cárdenas, buscaban participar en la política nacional en torno a la figura de un caudillo revolucionario. Finalmente, en 1951, la Federación de Partidos del Pueblo Mexicano (FPPM) se convirtió en el eje de un enfrentamiento político y social contra el régimen de Miguel Alemán. Lizbeth Castillo Farjat, "La oposición revolucionaria en el proceso electoral" de 1952-1954) (Tesis, Maestría en Historia, El Colegio de San Luis, 2009) 61-62.

${ }^{101}$ Luis Antonio García S., Efemérides sinaloenses (México: Comisión Estatal de Sinaloa, 2010) 226.

${ }^{102}$ Archivo General de la Nación, México, Fondo Dirección Federal de Seguridad, Versiones públicas de la Universidad Autónoma de Sinaloa (UAS), 100-23-legajo 1, fs. 301-302.

${ }^{103}$ Participó en 1966 en el movimiento estudiantil que destituyó al Dr. Julio Ibarra Urrea y para 1972 apareció en la Liga de Comunidades Agrarias "Lázaro Cárdenas", que era la línea disidente de la Liga de Comunidades Agrarias del Estado de Sinaloa (oficial). Archivo General de Nación (AGN), México, Fondo Investigaciones Políticas y Sociales (IPS), Caja 122-A, Exp. 1, f. 35.

${ }^{104}$ En 1966 Sánchez Duarte participó en la protesta -encabezada por los estudiantes de la Facultad de Derecho- contra la reelección del rector la UNAM, Ignacio Chávez (quien había llegado al poder en 1961). Los líderes estudiantiles tuvieron vínculos con algunos altos funcionarios del gobierno, así como de políticos priistas. Imanol Ordorika, Disputa por el Campus. Poder, política y autonomía en la UNAM (México: Universidad Autónoma de México y Plaza y Valdez, 2006) 135-136.

${ }^{105}$ Originario del poblado de Tenchoquelite, municipio de San Ignacio, nació el de abril de 1931, hijo de Miguel García Núñez y Joaquina Salcido. Contaba con un bufete jurídico. Estudió la primaria en la escuela Urbana Federal de Eldorado; su secundaria en la escuela federal No.1, para hijos de trabajadores de la ciudad de Tepic, Nayarit; y su preparatoria en la Escuela Nacional Preparatoria de la ciudad de México. Fue miembro de la barra de abogados "Eustaquio Buelna", de Culiacán. Según su ideología era de corte Marxista-leninista. Se desempeñó como defensor auxiliar adscrito a la jefatura del cuerpo de Defensores de
} 
Sociales de la UNAM, fungió como profesor de la Universidad desde 1955 a 1970, también se desempeñó como secretario general de la UAS de 1966 a 1970; y de 1972 a 1973 ocupó la rectoría de la UAS. ${ }^{106}$ Otro fue el Lic. Rodolfo Monjaraz Buelna (miembro del Partico Comunista Mexicano (PCM) ${ }^{107}$ quien realizó sus estudios de preparatoria en la Universidad Socialista del Noroeste de 1939 a1940. Estudió la carrera de Derecho en la Facultad de Derecho y Ciencias Sociales en la UAS de 1941 a 1943; y se desempeñó como catedrático en la Facultad de Derecho y rector de la UAS de 1966 a $1970 .{ }^{108}$

Una pléyade de estudiantes universitarios participaron en el movimiento político. Entre los que destacan, Salvador Lozano Quintero, miembro del Frente Estudiantil Sinaloense, que proponía reformas democráticas al interior de la administración universitaria y las organizaciones estudiantiles como las sociedades de alumnos y de la misma FEUS. Utilizaba como mecanismo de difusión el periódico estudiantil denominado Nueva Conciencia, que era financiada por el PRI y del que sólo vieron la luz dos números, pues cuando los editores, intentaron incluir artículos marxistas el partido oficial se negó a seguir subsidiándolo. ${ }^{109}$

Benito Flores, ${ }^{110}$ estudiante de contabilidad decía "que con apoyo del estudiantado de Sinaloa, formaran un grupo juvenil dentro del 'Francisco I. Madero, cuyo asesor y coordinador general es y será Enrique Peña Batiz, arrogó que su única arma contra las autoridades es la oratoria". ${ }^{111}$ Los estudiantes de leyes aparecieron como activistas de primera línea, entre ellos estaban José Refugio Ibarra Romero, Jaime Zazueta Palazuelos, ${ }^{12}$ y Robespierre Lizárraga, quien se ostentaba como vocero de los estudiantes universitarios y terminó afirmando en una reunión que "un gran contingente universitario sinaloense estará presente en la asamblea para

Oficio del estado; así como Juez Segundo de Primera Instancia del Ramo Civil y Juez Tercero de Primero Instancia del Ramo Penal. Participó en el movimiento contra el rector de la UAS Lic. Gonzalo M. Armienta Calderón.

${ }^{106}$ AGN, IPS, Caja 122-A, Exp. 1, f. 238.

${ }^{107}$ Nació en Culiacán, el 10 de abril de 1917. Realizó su primaria en la escuela federal tipo de 1923 a 1929; la secundaria en el Colegio Civil Rosales de 1930 a 1933. En 1933 Monjaraz Buelna ingresó la carrera de maestro en la Escuela Normal del Colegio Civil Rosales y, terminó en 1936; en 1941 inició la carrera de Derecho en la Facultad de Derecho de la UAS y, culminó en 1944. Monjaraz Buelna también fungió como profesor de secundaria, preparatoria, Normal y de Derecho de la UAS (1936-1970). Además, ocupó cargos como de asesor técnico en la Dirección General de Educación en el Estado de Sinaloa; Procurador General de Justicia del Estado de Sinaloa, durante el gobierno de Pablo Macías Valenzuela (1945-1950); asesor y director jurídico del Ayuntamiento de Culiacán; Director de la Facultad de Derecho y Ciencias Sociales; y Director del Bufete Jurídico Estudiantil de la Facultad de Derecho.

${ }^{108}$ Luis Antonio García, 227-229.

${ }^{109}$ Miguel Ángel Rosales Medrano, Altibajos. Las UAS: vicisitudes de su desarrollo (México: Universidad Autónoma de Sinaloa, 1994) 74.

${ }^{110}$ Flores Díaz durante el ciclo escolar 1966-1967, apareció como Secretario, junto con el presidente Ernesto Casillas Franco, de la Sociedad de Alumnos de Contabilidad. Para el periodo 1967-1968, Flores Díaz ascendió a la presidencia de la Sociedad de Alumnos. Para el periodo, 1968-1969, Flores ocupó la vicepresidencia de la FEUS.

${ }^{111}$ AGN, México, Fondo DFS, Versiones públicas de la UAS, Caja 100-23, legajo, 1, f. 44.

${ }^{112}$ AGN, México, Fondo DFS, Versiones públicas de la UAS, Caja 100-23, legajo, 1, fs. 301-302. 
formar el Comité Estudiantil Juvenil Maderista". ${ }^{113}$ A esa consigna se sumaron los estudiantes Juan Manuel Terrazas, Anacleto Terrazas Araujo (presidente de la FEUS para el periodo, 1966-1967), Jesús Miche Jacobo "El Hitler", ${ }_{14}$ quien ocupó la presidencia de la FEUS en el periodo 1967-1968; así como Andrés Cañas Martínez, ${ }^{115}$ que "está promoviendo y buscando prosélitos para el grupo Juventudes Profesionales Estudiantiles de Sinaloa, que pretenden formar un partido Nacional Juvenil". ${ }^{116}$

En la Universidad existieron dos polos de activismo político, uno fue en la escuela de Derecho y el otro en la escuela de Economía. Los primeros eran mayoritarios, por lo tanto fueron ellos los que estuvieron en primera línea en el grupo encabezado por Peña Batiz y, además que era tradición que los estudiantes de derecho realizaran carrera política dentro de la Universidad, para luego brincar a la arena estatal. El grupo de Derecho fue el que impuso su hegemonía hasta 1968, después comenzó la etapa de la Juventudes Comunistas.

En Economía emergió un núcleo más radical, cuyo ideólogo principal fue el profesor José Luís Ceceña Cervantes, ${ }^{117}$ quien era de ideología marxista y simpatizante

\footnotetext{
${ }^{113}$ AGN, México, Fondo DFS, Versiones públicas de la UAS, Caja 100-23, legajo, 1, fs. 324-326.

${ }^{114}$ Este alumno participó el movimiento de huelga de 1966, cuando renuncio Julio Ibarra Urrea. En los informes de Seguridad del gobierno federal se le caracterizaba como destacado "orador y muy fogoso, es decir muy conativo, a últimas fechas y probablemente siguiendo el doble papel se ha lanzado en insultos contra el gobierno federal, principalmente el estatal. Estuvo en contacto con el Comité Nacional de Huelga en 1968; asistió al festival Mundial de la Juventud Comunista, celebrado en Sofía Bulgaria.

${ }^{115}$ Cañas Martínez, en periodo 1966-1967, ocupó la cartera de Acción Cultural y Festejos en la FEUS; asimismo, fue delegado por la Facultad de Derecho, ante dicha agrupación. Participó como orador en los movimientos estudiantiles de la UAS, la Normal y en la Secundaria de Novolato. En 1967, participó en el primer Consejo Nacional de la CNED.

${ }^{116}$ AGN, México, Fondo DFS, Versiones Publicas de la UAS, Caja 100-23, legajo, 2/16, f. 349.

${ }^{117}$ Ceceña Cervantes, nació en Culiacán, el 10 de agosto de 1937, fue hijo del Licenciado en Economía y periodistas José Luis Ceceña, quien fungió como director de la Escuela de Economía de la UNAM en 1970. Ceceña estudió primeria en el Centro Escolar Revolución; la secundaria y preparatoria en la escuela Nacional Preparatoria y, su carrera profesional en la Escuela Nacional de Economía de donde se tituló el 26 de julio de 1960, sustentando la tesis: "El Mercado del tomate sinaloense y sus principales problemas". Ha sido asesor de la UAS en el Desarrollo Agricultura, Ganadero y Forestal del Estado y del Consejo de Promoción Industria y Desarrollo Económico del Estado; Asesor Económico en la Tesorería del Estado. Publicó algunos trabajos como: "El Proyecto del tomate sinaloense y sus principales problema; El Proyecto de Ley Federal de Planeación y otros tantos sumando un total de 31 publicaciones. De 1956 a 1959, trabajó como auxiliar de Economista en la Sección de Planeación Industrial del Departamento de Investigación Industrial del Banco de México; de 1959 a 1969 laboró como economista en la Dirección General de Precios de la SIC; al tiempo que fue miembro del Consejo Superior Ejecutivo del Comercio Exterior en la Secretaría de Relaciones Exteriores. Del $1^{\circ}$ de noviembre de 1961 al 9 de abril de 1970, fue director de la Escuela de Economía de la UAS. Las materias que impartió como profesor fueron las siguientes: Teoría Económica, Teoría de las Finanzas; Finanzas Publicas de México; Seminario sobre organización y financiamiento de empresas; Economía; Teoría Económica y Social de Marxismo; Teoría del Desarrollo Económicos; Teoría y técnica de la planificación; Desarrollo económico de Sinaloa; Seminario sobre filosofía y carrera de economista. Participó en el movimiento contra Armienta Calderón y fue aspirante a la rectoría en 1970 y 1972.
} 
del PCM. ${ }^{118}$ Ceceña formó parte del Frente Electoral del Pueblo (FEP), ${ }^{119}$ que era dirigido por el profesor Arturo Campos Román. ${ }^{120}$ Siendo director de la Escuela de Economía, en 1966 Ceceña en plena huelga estudiantil, coincidía con el Comité Estatal del PCM en su apoyo a los huelguistas, porque el rector Dr. Julio Ibarra para construir Ciudad Universitaria solicitó un préstamo al Banco Interamericano de Desarrollo, que;

En lo personal, si lo estaba por considerar que esa obra era un elefante blanco, sumamente costosa y no proporciona mejoramiento académico, pues no son 30 millones de pesos, los que se necesitan para esa construcción, sino 90 millones, por lo que se está engañando al pueblo. ${ }^{121}$

Ceceña como principal ideólogo del núcleo de Economía, se convirtió en flanco de ataques constantes por parte del rector Ibarra Urrea y de la prensa local. Se publicó un documento donde se exhibió que Ceceña recibía mensualmente, la cantidad de 7, 250 pesos de parte del Fondo de Cultura Popular, editorial del Partido Comunista. ${ }^{122}$

Junto a Ceceña estaba la profesora Silvia Millán y el joven profesor Manuel Inzunza Sáenz, ${ }^{123}$ quien había sido un buen estudiante y como catedrático "según sus

\footnotetext{
${ }^{118}$ AGN, México, Fondo Dirección General de Investigaciones Políticas y Sociales (DGIPS), Caja 122-A, Exp. 1, fs. 248-249.

${ }^{119}$ Para competir en las elecciones de 1963-1964, se fundó el FEP, que respondía a una exigencia de los sectores más radicalizados de las masas, sobre todo de los campesinos, que veían en él un agrupamiento para oponerse a la política de la burguesía gobernante, incluso en el terreno electoral, buscaba una posición antiimperialista. El FEP, logró movilizar las masas en torno a la candidatura de Ramón Danzos Palomino, revelando el incremento de los sectores interesados a una salida revolucionaria. Arnoldo Martínez Verdugo, Partido Comunista Mexicano. Trayectoria y perspectivas (México: Partido Comunista Mexicano, s/f) 40.
}

${ }^{120}$ Según las Dirección de Seguridad, aprovechaba sus cátedras y su docencia entre el estudiantado para adoctrinarlos y hacerlos adeptos a su ideología de izquierda radical. AGN, México, Fondo DFS, Versiones públicas de la UAS, Caja 100-23, legajo 1, f. 434.

${ }^{121}$ AGN, México, Fondo DFS, Versiones públicas de la UAS, Caja 100-23, legajo 1, fs. 483-485.

${ }^{122}$ AGN, México, Fondo DFS, Versiones públicas de la UAS, Caja 100-23, legajo 1, fs. 483-485.

${ }^{123}$ Inzunza Sainz nació el 16 de marzo de 1943 en Culiacancito, municipio de Culiacán, hijo de Manuel Inzunza y Gloria Sainz. Culminó su primaria en la escuela general Ignacio Zaragoza, del poblado de Culiacancito; la secundaria y la preparatoria la realizó en la Escuela Normal de Sinaloa de donde se graduó como maestro el 19 de febrero de 1965, con la tesis: "La enseñanza auditivo-visual en la escuela Primaria". Asimismo, ingresó a la Escuela de Economía de la UAS, que terminó el 13 de octubre de 1967, con la tesis: "La sub-ocupación de la fuerza de trabajo y la economía en Sinaloa". En 1969, Inzunza llevó a cabo un curso La Comercialización nacional e internacional de postgraduado en Río de Janeiro, Brasil. De 1961 a 1972 fue profesor de primaria, maestro de Economía en la Universidad de Sinaloa; Director del Departamento Editorial de la Dirección General de Educación en el Estado de Sinaloa; Secretario de la Escuela de Economía; Economista de la Tesorería General del estado de Sinaloa, adscrito a la Dirección de Inversiones y Obras Públicas en la Oficina de Evaluación y Control de Crédito, de abril de 1969 a mayo de 1970 y, jefe de oficina de Programación de Obras de Infraestructura; jefe del Departamento de Planeación y Programación de la Ciudad Universitaria de Sinaloa; Jefe de Departamento de Educación Socioeconómicos de la Dirección de Acuacultura de la Secretaria de Recursos Hidráulicos. Del 12 de abril al 22 de mayo desempeñó el cargo de secretaria general de la UAS, cargo al que renunció para lanzarse como candidato a la rectoría. En 1967, participó en la IV Reunión de Escuelas y Facultades de Economía de América Latina, en Perú. En 1972, Inzunza fue aspirante a rector de la UAS, pero por su edad fue una limitante. Las cátedras que imparte en las diferentes escuelas y facultades de la UAS: Teoría General de las Finanzas Públicas; Tesorería del Comercio Internacional; Filosofía, Lógica, Nociones de economía, Métodos y 
propios alumnos, excelente"; ha participado en diferentes cursos y eventos en México y en el extranjero; y como estudiante viajó a la República Socialista de Cuba. ${ }^{124}$ Por el lado estudiantil, destacaba Fausto Burgueño Lomelí (originario del municipio de Cosalá), quien fungía como presidente de la Sociedad de Alumnos de la Escuela de Economía. Él fue uno de los dirigentes principales que se manifestó contra el rector Dr. Julio Ibarra Urrea en 1966 e incluso lo reto "enfrentársele como hombre, no como señorita frustrada". Burgueño Lomelí siempre fue abierto a que participaran en la huelga "maestros, directores de escuelas y estudiantes en general, sin distinción de ideologías". ${ }^{125}$ Otro estudiante fue Horacio Lozano Santillán, quien era profesor de Secundaria y estudiante de Economía, al mismo tiempo participaba en el grupo Francisco I. Madero. ${ }^{126}$ También destacaron los alumnos Daniel García Mascareño, Salvador Lizárraga Saucedo, José de Jesús Montiel Montoya, Cesar García Vargas y Rodrigo Rodríguez Mendoza. ${ }^{127}$

Una generación había derrotado al Dr. Julio Ibarra Urrea, quien antes de renunciar como rector en octubre de 1966, realizó una radiografía de sus detractores al decir:

He demostrado que los tres movimientos que en la corta vida de la autonomía que tienen la institución, se ha suscitado, fueron generados y financiados por partidos políticos en la lucha por el poder y evidenciado la intervención descarada del Partido Comunista Mexicano, del llamado grupo Francisco I. Madero, de seudo universitarios secundados en puestos públicos, de exfuncionario será sus muy personales intereses. ${ }^{128}$

Los cuadros progresistas del PRI, con el triunfo del movimiento estudiantil en 1966, lograron sentar las bases de su proyecto político en la Universidad. Mientras que el PCM comenzó a tener presencia en la Escuela de Economía por medios de estudiantes y maestros, ya que a nivel nacional el partido había centrado su mirada hacia los trabajadores agrícolas, los campesinos sin tierra, los trabajadores del sector estatal, los cristianos radicalizados; los jóvenes y los estudiantes. ${ }^{129}$ Las dos corrientes políticas abrazaron como proyecto político democratización de las organizaciones universitarias, agrarias y obreras. Uno de los alumnos sostenía: "este es una organización comunista, son totalmente falsos, ya que el "Francisco I. Madero", es revolucionaria y democrático y cuenta con todo el apoyo del Sr. Presidente de la Republica". Además, los universitarios querían construir un partido político que compitiera con los candidatos impuestos por los caciques del PRI.

técnicas de investigación social, Estadísticas aplicadas a la Economía y a los negocios; Economía Social e Investigación.

${ }^{124}$ AGN, México, Fondo DGIPS, Caja 122-A, Exp. 1, f. 246.

${ }^{125}$ AGN, México, Fondo DFS, Versiones públicas de la UAS, Caja 100-23, legajo 1, fs. 483-485.

${ }^{126}$ AGN, México, Fondo DFS, Versiones públicas de la UAS, Caja 100-23, legajo 1, f. 73.

${ }^{127}$ AGN, México, Fondo DFS, Versiones públicas de la UAS, Caja 100-23, legajo 1, fs. 65-66.

${ }^{128}$ AGN, México, Fondo DFS, Versiones públicas de la UAS, Caja 100-23, legajo 1, fs. 1 y 2.

${ }^{129}$ Barry Carr, La izquierda mexicana a través del siglo XX (México: Ediciones Era, 1996) 230-231. 
La generación que participó en el grupo Francisco I. Madero y en la izquierda comunista (PCM) y marxista nacieron durante la etapa de estabilidad económica, de 1940 en adelante, por cerca de cuarenta años, el producto nacional bruto alcanzó un crecimiento promedio anual del 6 por 100. Pero comenzaron a aparecer serios problemas en el modelo económico durante la segunda mitad de los años sesenta, donde los presidentes anunciaron administrar la abundancia, gracias a los grandes recursos petroleros. ${ }^{130}$

\section{El ascenso de la izquierda en la Universidad}

El núcleo duro de la izquierda en la Universidad, sobre todo marxista se asentó en la Escuela de Economía, su máximo ideólogo fue el Lic. José Luís Ceceña, quien desde 1966 hasta 1967, cuando el PCM no tenía presencia en la Universidad, se encargó del proceso de adoctrinamiento de los alumnos de la citada escuela. Por ejemplo, en 1967 Ceceña organizó un viaje a la Habana, Cuba, lo acompañaron los profesores Manuel Inzunza (secretario de la Escuela de Economía), Silvia Millán y el profesor de Artes Plásticas Arturo Moller y el estudiante de Economía Fausto Burgueño Lomelí entre otros. ${ }^{131}$ Según la DFS, Ceceña llevó a la Isla a los alumnos a obtener conocimientos de tácticas guerrilleros, brigadas de choque y habilidades para agitar en el medio estudiantil. ${ }^{132}$ El mismo director de Economía y el estudiante Burgueño Lomelí, en junio de 1967, mostrado admiración por la Revolución Cubana efectuaron la Semana cultural cubana e invitaron al embajador Dr. Joaquín Hernández. ${ }^{133}$

Las conferencias fueron otras formas de ideologización en la Escuela de Economía. Para eso, Ceceña Jr. contaba con su padre, José Luís Ceceña Gámez, de filiación comunista, ${ }^{134}$ quien disertó el tema: Desarrollo económico. El conferencista enfatizo en temas como las siguientes: existe un paupérrimo ingreso económico de las clases populares; el gobierno debe acabar con los monopolios y nacionalizar la banca. Terminó diciendo, que la "revolución popular se lograra en el campo y en la fábrica, orientando al campesino y al obrero sobre sus legítimos derechos, para que pida respeto ante el patrón, empresa o gobierno. ${ }^{135}$

\footnotetext{
${ }^{130}$ Lorenzo Meyer, "La prolongada transición mexicana: ¿del autoritarismo hacia dónde? Revista de Estudios Políticos 74 (1991): 365.

${ }^{131}$ AGN, México, Fondo DFS, Versiones Publicas de la UAS, Caja 100-23-1, legajo 2/16, f. 411.

${ }^{132}$ AGN, México, Fondo DFS, Versiones Publicas de la UAS, Caja 100-23-1, legajo, 2/16, f. 304.

${ }^{133}$ AGN, México, Fondo DFS, Versiones Publicas de la UAS, Caja 100-23-1, legajo, 2/16, f. 375.

${ }^{134}$ AGN, México, Fondo DFS, Versiones públicas de la UAS, Caja 100-23, legajo 1, f. 163.

${ }^{135}$ AGN, México, Fondo DFS, Versiones públicas de la UAS, Caja 100-23, legajo 1, f. 165.
} 
Rodolfo Rodríguez Meléndrez "El Chichi”, ${ }^{136}$ jugó un papel importante en la creación de cuadros políticos dentro de la universidad, lo cual fue aprovechado por la Juventud Comunista de México (JCM). Al respecto Millán Alarid recuerda:

Rodríguez Meléndrez, este tenía un Ateneo que se llamaba Señor Universitario, donde muchos de nosotros nos preparaban como oradores, el caso de Liberato [Terán Olguín] por qué Liberato era bien tartamudo y lo ponían a practicar con un lápiz en la boca, y lecturas en voz alta, entonces Rodríguez Meléndrez jugó un papel importante, ante el movimiento de marzo de la universidad y, la gente del Partido Comunista, es el que toma el trabajo de este señor y, se empieza como era, una organización nacional, se empieza más fácil a penetrar, Rodríguez Meléndrez finalmente va a salir expulsado de la casa del estudiante [Rafael] Buelna y por la misma gente de la Juventud Comunista. ${ }^{137}$

Rodríguez Meléndrez dirigía el Ateneo Universitario, que realizaba reuniones los fines de semana en el Auditorio Ruperto L. Palizada, ubicado en el edificio central de la UAS, donde se cursaba oratoria, poesía, asimismo se proyectaba cine universitario y se efectuaban festivales culturales. Liberato Terán, igual que Millán Alarid, coinciden en que el Ateneo fue un crisol ideológico- político de las sociedades de alumnos y de la FEUS, el motor del conjunto de iniciativa que desplego el movimiento universitario de los sesenta y setenta. En el ateneo se discutía y argumentaba en torno a la Revolución cubana, disputa chino-soviética, la condena de la guerra Vietnam, la teoría del foco guerrillero. La agrupación contaba con su propio periódico denominado: Trinchera. ${ }^{138}$

La presencia del PCM en la Universidad antes de 1968, se encontraba dispersa, si acaso existían algunos profesores como Monjaraz Buelna y, Ceceña Cervantes comulgaba con el marxismo, pero no formaba parte del Partido. El profesor

\footnotetext{
${ }^{136}$ Rodríguez Meléndrez, desde joven su madre Lorenza "Lenchita”, le puso el apelativo de "Chichí". Nació en ciudad Obregón, Sonora, el 27 de marzo de 1940. Fue hijo de ejidatario y formado en los años sesenta en los círculos culturales con Juan Eulogio Guerra. Desde temprana edad "Chichi”, viajaba cada año con su madre a la sierra Tarahumara, cargados de alimentos y ropaje para los más pobres de los indígenas rarámuri. Rodríguez Meléndrez, ingresó a la Facultad de Derecho de la UAS alrededor de los años sesenta, ahí conoció a uno de sus maestros el Lic. Marco Cesar García Salcido, con quien participó activamente (19651966) en el grupo Francisco I. Madero, dirigido por Enrique Peña Batiz. El gobernador Leopoldo Sánchez Celis respondió con represiones contra los militantes del grupo político, así que Rodríguez Meléndrez tuvo que salir del estado, regresó nuevamente cuando estalló la huelga contra el rector Julio Ibarra Urrea a finales de 1966. En 1968 "Chichí" fundó la Casa del Estudiante Universitario Rafael Buelna Tenorio, del cual fue su presidente; en ese mismo año junto con Fausto Burgueño Lomelí crearon la preparatoria Popular Emiliano Zapata. El aludido orador participó en el movimiento de 1968, pero a finales de 1969, se marchó a Sonora. Millán Alarid, considera que lo hizo porque se decepcionó de su maestro, García Salcido quien se registró como aspirante a la rectoría de la UAS ante la Junta de Gobierno, contradiciendo a la FEUS que proponía voto universal y un referéndum. Janeth Aldecoa, "Recuerdan al luchador incansable", Noroeste, Culiacán, 31 de mayo de 2016; Alejandro de la Torre D., "El Chichí Meléndrez ejemplo de enjundia y capacidad de asombro", Crónica 10, Cajeme, Sonora, 26 de mayo de 2016. http://revistacronica10.blogspot. com/2016/06/rodolfo-rodriguez-el-chichi-melendrez.html

${ }^{137}$ Alfredo Octavio Millán Alarid, "entrevista citada".

${ }^{138}$ Sergio Arturo Sánchez Parra, Estudiantes en armas. Una historia política y cultural del movimiento estudiantil de los Enfermos (1972-1978) (México: Universidad Autónoma de Sinaloa y Academia de Historia de Sinaloa A.C, 2012) 109
} 
Arturo Campos Román comenzó a aparecer después de 1968, aunque este si había sido uno de los militantes más activos del PCM en Sinaloa, pues fue candidato a senador en 1965, por el Frente Electoral del Pueblo, así como secretario del Comité Central Regional de Sinaloa del PCM. ${ }^{139}$

A nivel nacional, la Revolución cubana y su compromiso con la revolución continental habían estimulado la politización de una nueva generación de estudiantes. Así que la Juventud Comunista de México ${ }^{140}$ experimentó un renacimiento en la UNAM y en el IPN, en la ciudad de México, y atrajo a figuras como Rafael Talamantes, Raúl Álvarez, María Fernanda Campa, Valentina Campa, Walter Ortiz, Eliezer Morales, Gilberto Guevara y Pablo Pascual, muchos de los cuales desempeñarían un papel relevante en la izquierda mexicana durante los siguientes dos décadas. ${ }^{141}$

Pero en Sinaloa fue entre 1967 y 1968, cuando llegaron los representantes de la JCM, quienes se ocuparon de organizar los cuadros juveniles en la entidad y en la Universidad. Uno de ellos fue Eduardo Valle Espinoza ( $\mathrm{El} \mathrm{Búho)}{ }^{142}$ estudiante proveniente de la UNAM, quien traía consigo todo un bagaje de experiencia política adquirida de los incipientes movimientos estudiantiles que comenzaban a surgir en México. Una de sus mayores contribuciones a la lucha estudiantil en la UAS, fue su destacada actuación en la elaboración del anteproyecto de una Nueva Ley Orgánica, presentado por la FEUS; propuesta que luego retomó el conjunto del movimiento, hasta discutirse en detalle y aprobarse en el Consejo Universitario como iniciativa de ley, misma que se llevó al Congreso del Estado y se ventiló en un debate público. ${ }^{143}$

También arribaron a la UAS otros dos jóvenes, destacados militantes comunistas: Antonio Medina de Anda, que se inscribió en la Escuela de Agricultura; y Antonio Pacheco Ortiz que se matriculó en la Escuela de Economía, ambos habían participado en las luchas de la Universidad de Guadalajara (UDG, lugar de donde

\footnotetext{
${ }^{139}$ AGN, México, Fondo DFS, Caja 100-23-1, Versiones Publicas de la UAS, Caja 100-23-1, legajo, 2/16, f. 90.

${ }^{140}$ Los militantes estudiantes del PCM rescataron y democratizaron las federaciones estudiantiles y las sociedades de alumnos; más tarde promovieron una gran asociación estudiantil independiente del Estado: la Central Nacional de los Estudiantes Democráticos (CNED), cuyo primer antecedente fue la Conferencia de Morelia en mayo de 1962. El Partido ofreció un diagnóstico de la crisis de la educación y proponía la reforma democrática de la educación superior. Otras cuestiones era la lucha por la democratización de las estructuras del gobierno interno de las instituciones educativas y contra la aristocratización de la enseñanza. Fabio Barboa Cano, “Acción y búsqueda programática”, Arnoldo Martínez Verdugo, Historia del comunismo en México (México: Editorial Grijalbo, 1983) 304-307.

${ }^{141}$ Barry Carr, 233.

${ }^{142}$ Nació en Ciudad de México, el 10 de marzo de 1947. Su madre fue Celia Espinoza Díaz y su padre, Cosme Valle Miller. Estudió en la Escuela primaria en la Colonia Balbuena y al graduarse entró a la preparatoria Dos-UNAM, donde cursó la secundaria y la preparatoria. Ligado a Sinaloa por su familia paterna participó en la FEUS y en el movimiento estudiantil. En 1967 ingresó en la ciudad de México a la filas de la Juventud Comunista y entre Marcelino Perelló, Gilberto Guevara, apoyados por La Chata Campa (hija de Valentín Campa) y de Raúl Álvarez Garín. En el mes de marzo de 1968 ganó el primer lugar en poesía en los VI Juegos Florales de la UAS con el poema "Oraciones Nocturnas" y después de pasar algunos meses en Sinaloa, regresó a la ciudad de México.

${ }^{143}$ Wikipedia, "Eduardo Valle 'El Búho", 26 de julio de 2020. https://es.wikipedia.org/wiki/Eduardo_ Valle_\%22El_B\%C3\%BAho\%22
} 
fueron expulsados por la Federación de Estudiantes de Guadalajara (FEG). Pronto estos dos estudiantes destacaron como dirigentes estudiantiles; "Toni" Medina había sido dirigente en la Juventud Comunista en Guadalajara, junto con su tocayo el "Toni" Pacheco. Decidieron irse a Sinaloa donde cayeron parados. Al rato ya eran jefes de la Juventud, hasta del movimiento estudiantil". ${ }^{144}$

Así fue como en la UAS se conformó el cuadro político de militantes comunistas integrado por Liberato Terán Olguín ${ }^{145}$ y sus hermanos Rito y Lorenzo, así como Audómar Ahumada Quintero, Camilo Valenzuela Fierro, Eleazar Salinas Olea, Francisco Rivera (Chicano), Guillermo Juangorena Tamayo, José Antonio León Mendívil, Andrés Ayala (El Rayo) y Jorge Luna Lujano. ${ }^{146}$ Esta corriente poco a poco fue consolidando su protagonismo al interior del movimiento estudiantil y por su puesto en la FEUS.

En una primera fase, Liberato Terán - de segundo año de Economía- fue el que destacó dentro de la FEUS, ${ }^{147}$ ocupó el cargo de presidente del Comité Ejecutivo durante el periodo 1968-1969. Con Liberato se dio un parteaguas, primero porque al ser derrotado el grupo de Mazatlán encabezado por Castro Zamudio, se terminó con la hegemonía en la FEUS de los estudiantes de Derecho. Segundo, Terán Olguín se distanció de sus antecesores, pues desarrolló una política cultural ${ }^{148}$ entre el estudiantado, además que trató de vincularse a los movimientos populares. Liberato siendo estudiante de segundo

\footnotetext{
${ }^{144}$ Gustavo Hirales Morán, Memoria de la guerra de los justos (México: Cal y Arena, 1996) 122.

${ }^{145}$ Liberato nació en San Ignacio Tamazula, Durango, México; marzo 22 de 1947, sus padres fueron Eusebio Terán Quiñónez y Beatriz Olguín Quiñónez, cuarto de cinco hermanos: Lorenzo, Clemencio, David y Rito. Estudió la primaria en las escuelas públicas rurales de Tamazula, Topia, Durango; y Corerepe, Guasave, Sinaloa (1950-1953 y 1956-1962); secundaria en la escuela Federal por Cooperación "Insurgentes" Guasave, Sinaloa (1962-1965); nivel medio superior en la preparatoria Central Diurna de la UAS (1956-1967). Licenciatura en Economía en la UAS (1967-1972); maestría en Economía en la Facultad de Economía de la UNAM (1973-1975. Terán Olguín ocupó diferentes cargos sociales y políticos: Delegado consejero universitario estudiante 1966-67, 1968-70,1970-71, en la UAS; Presidente de la Federación de Estudiantes Universitarios de Sinaloa (FEUS): 1968-70; Miembro del Comité Ejecutivo Nacional de la Central Nacional de Estudiantes Democráticos (CNED): 1967-69; Delegado por CNED ante el Foro Mundial por la Paz (Berlín), Unión Internacional de Estudiantes (Praga) y Organización Continental Latinoamericana de Estudiantes (La Habana), en 1969; Vicepresidente y Presidente del Frente de Defensa Popular (FDP): 1969-70; 1970-72; Candidato a Diputado Local (Culiacán), sin registro, por el Partido Comunista Mexicano (PCM): 1980. Cesar Velázquez, "Liberato Terán”, Politeia (2013).

${ }^{146}$ Mauricio Laguna Berber, Liga comunista 23 de septiembre (LC23S) (s/1 y s/f) 6.

${ }^{147}$ A fines de 1968, Benito Flores propuso a Liberato Terán para presidente del Comité Ejecutivo de la FEUS, por su destacada participación en la lucha estudiantil; mientras que Enrique Hubbard, lanzó la candidatura de del estudiante de Derecho, Jorge Castro Zamudio argumentando que se debe dejar de lado la política y dedicarse a los problemas internos de la UAS. Se sometió a votaciones, Terán Olguín obtuvo 20 votos; y Castro Zamudio se quedó con 9 votos.

Con el advenimiento del rectorado de Gonzalo Armienta Calderón (1970-1972), el grupo de Mazatlán encabezado por Castro Zamudio se alineó a su rectorado. Archivo Histórico de la Universidad Autónoma de Sinaloa (AHUAS), Fondo Liberato Terán, Acta de la Federación de Estudiantes Universitarios de Sinaloa, Culiacán, Sinaloa, 23 de noviembre de 1968, p. 12.

${ }^{148}$ Liberato encabezó algunos mítines, sin embargo le apostó educar a las masas estudiantiles a través de Festivales culturales donde los alumnos y maestros declamaban poesía de crítica al gobierno y al imperialismo; así como conferencias sobre la Guerra de Vietnam, al tiempo que se cantaba música de protesta.
} 
año de la preparatoria Central Diurna en mayo de 1966, participó y obtuvo el primer lugar en el concurso Estatal de Oratoria organizado por la FEUS. Gracias a eso, resultó electo como representante del Consejo Universitario y para septiembre participó con la generación joven en la huelga contra Julio Ibarra Urrea. ${ }^{149}$

Después de la renuncia de Ibarra Urrea, Liberato en una de sus intervenciones sostenía "los estudiantes debemos ser de hoy en adelante los paladines de la justica y que aunque se nos ha calificado de marxistas, anarquistas, comunistas, agitadores, luchamos por verdad". ${ }^{150}$ En lapso de 1967-1969, Terán Olguín fue integrante del comité Nacional de la JCM. Liberato aunque más joven sigue siendo parte de la generación que abrazó el proyecto del grupo Francisco I. Madero, sólo que se nutrió de la vena intelectual de Ceceña Cervantes y su habilidad por la oratoria lo perfeccionó con Rodríguez Meléndrez. Mientras que Ahumada Quintero, Valenzuela Fierro, Salinas Olea, Juangorena Tamayo, León Mendívil, Francisco Rivera, Andrés Ayala (El Rayo) y Luna Lujano llegaron a la Universidad entre 1968 y 1969, cuando la Universidad estaba politizada y la JCM controlaba las casas del estudiante Rafael Buelna Tenorio y La Sinaloense. Por ejemplo, Valenzuela Fierro, Ahumada Quintero (oriundos de municipio de Guasave), Salinas Olea (originario de Culiacancito, a unos kilómetros de Culiacán) y León Mendivil se instalaron en las casas estudiantiles, compartiendo habitación con uno de los dirigentes de la JCM Pacheco Ortiz. ${ }^{151}$

La FEUS encabezada por Liberato Terán, para formar los cuadros políticos implementó como pedagogía los festivales culturales, que incluía música de protesta, poesía crítica y conferencias. La música fungió como fuente de inspiración e identificación con otras personas que comparten su causa. Además la música se baila, se grita, se canta; y todo eso sucede en compañía de otras personas, se hace en sintonía con las bandas y con el público que las acompaña. En las marchas, aun cuando se esté denunciando algo considerado injusto, se respira ambiente de regocijo. Se gritan con coraje reprimido, se exige justicia a gritos, hay indignación y tristeza, pero detrás de todo ello hay alegría. ${ }^{152}$

En las reuniones celebradas en la escuela de Derecho y Contabilidad y Administración, Liberato Terán, Ismael Arenas y Lamberto Ortega organizaron un festival cultural, donde ofreció un concierto Margarita Bauche quien para ese tiempo se había convertido en una juglar del movimiento estudiantil mexicano; al igual que la compositora Judith Reyes. Para Bauche la música de protesta expresaba un descontento ante un "problema que afecta directamente a los hombres, a un país. La

\footnotetext{
${ }^{149}$ Entrevista a Terán Olguín.

${ }^{150}$ AGN, México, Fondo DFS, Versiones públicas de la UAS, Caja 100-23, legajo, 1/16, fs. 11 y 12.

${ }^{151}$ Entrevista de Rafael Santos Cenobio a José camilo Valenzuela Fierro, Guadalajara, Jalisco, 15 de octubre de 2005.

${ }^{152}$ Elí Orlando Lozano González, "Los ritmos de la rebeldía: la música en la formación política de estudiantes activistas universitarios", Revista de Ciencias Políticas y Sociales 237 (2019): 90. doihttp:// dx.doi.org/10.22201/fcpys.2448492xe.2019.237.67674
} 
protesta ante un mal sistema o ante lo que nos parece negativo o nos afecta". ${ }^{153}$ Entre los temas más importantes resaltaban: México 68, México te amo, Perseverancia, Vale la pena vivir, Rumba jarocha, La Morena, María, Regina, Madre Tierra, Niño Chamula, Soñé y Carreta de Madera. Algunos fragmentos de esta última canción dedicada al Che Guevara decía:

Los paisajes y los cerros Atrás quedándose están, con mi cantar yo me alejo, me alejo cada vez más.

Mi canto tiene un mensaje

De tristeza y soledad, tiene el sabor del silencio, del llanto lleva la sal.

Carreta de madera

Déjame donde tú ya no puedas andar,

Largo es mi camino

Mas tengo es mi camino

Más tengo que llegar.

Tengo en mi pueblo el hambre

y ahora busco libertad,

Pan no se necesita

Sin antes la paz lograr.

Los montes están inquietos,

Las flores quieren llorar,

Le digo adiós a mi suerte,

$\mathrm{Al}$ frente voy a luchar.

Los campos se están secando,

la limpia lluvia se va,

el agua se tiñe negra,

y negra la tierra esta.

Carreta de madera

Déjame donde tú ya no pueda andar,

Largo es mi camino,

Más tengo que llegar.

Tuve en mi pueblo el hambre,

Y ahora tengo libertad,

Será la vida eterna

Cuando se descanse en paz. ${ }^{154}$

Las canciones de protesta consumidas por los estudiantes, se coreaban en las reuniones, los mítines y las manifestaciones públicas, asimismo los mismos alumnos

\footnotetext{
${ }^{153}$ A. G. Torres Escobar, "Margarita Bauche: Libertad, justicia, amor, canción de protesta", 27 de abril de 2014. http://blancaauroramondragon.blogspot.com/2014/04/nocturno-rosa-margarita-bauche-y-hugo.html ${ }^{154}$ A. G. Torres Escobar.
} 
realizaban antologías de canciones, que repartían dentro de la misma Universidad con el fin de construir un discurso legitimador. Además de María Bauche, se cantaban las canciones de Judith Reyes, uno de los más famosos fue Los restos de Don Porfirio, donde se denunciaba el presidencialismo autoritario y la Constitución era una mera formalidad. ${ }^{155}$

Cuando Armienta Calderón, llegó a la rectoría de la UAS en 1970, los estudiantes se posesionaron del edificio central de la Universidad, quienes por medio de un equipo de sonido difundieron canciones de protesta. Asimismo, dos estudiantes de la preparatoria Emiliano Zapata entonaron canciones de protesta en homenaje a Ernesto Che Guevara; y la estudiante de Enfermería, Blanca Nieves Palacios, interpretó canciones de protesta. ${ }^{156}$

Dentro de los festivales culturales también se declamaba poesía, por ejemplo, en el atrio de Catedral, con asistencia de 400 personas, la FEUS auspició la presentación del Grupo Coral Político Mascaradas, quienes interpretaron siete poesías donde denunciaban al imperialismo yanqui; y al terminar el acto cultural el grupo vendió al público discos grabados por ellos. ${ }^{157}$ En otro acto cultural, el grupo de Poesía Coral de la preparatoria Popular Emiliano Zapata entonó los versos de una canción de protesta. ${ }^{158}$ Para principios de 1970, cuando estalló la huelga contra Armienta Calderón, cincuenta alumnos en la plazuela Rosales, frente al edificio central de la UAS, pusieron discos mediante el sonido local de la Universidad, donde colocaron grabaciones del Grupo Los Mascareños, que "contiene poesía de protesta, invitando a la concentración anunciada para las 5:00 horas frente a la Universidad". ${ }^{159}$

En México, después del 68, el viento de protesta, de denuncia, vertebra temáticamente las principales composiciones del 68. El tono acusatorio define una poesía directa, alusiva, donde el interés ideológico prima sobre las definiciones estéticas. La literatura va a abrir un proceso de reflexión sobre el estado de la patria y las consecuencias del desarrollo de una democracia aparente, autoritaria y represiva, con un doble discurso, cargado de grandes significados de progreso y vacía de soluciones reales ante las desigualdades sociales. ${ }^{160}$

Otro de los géneros socorridos por la FEUS, fueron las conferencias. En mayo de 1969, el organismo estudiantil invitó a la periodista, escritora, museógrafa y crítica de arte Raquel Tibol, ${ }^{161}$ quien fungía como Secretario de Organización del

\footnotetext{
${ }^{155}$ Rafael Santos Cenobio, "Discursos, símbolos e iconos de la disidencia: del movimiento estudiantil a la radicalidad en Sinaloa, México, 1966-1973”, Conjeturas Sociológicas 14 (2017) 24-25.

${ }^{156}$ AGN, México, Fondo DFS, Versiones Publicas de la UAS, Caja 100-23, legajo 2/16, f. 45.

${ }^{157}$ AGN, México, Fondo DFS, Versiones Publicas de la UAS, Caja 100-23, legajo 2/16, f. 52.

${ }^{158}$ AGN, México, Fondo DFS, Versiones Publicas de la UAS, Caja 100-23, legajo 2/16, f. 166.

${ }^{159}$ AGN, México, Fondo DFS, Versiones Publicas de la UAS, Caja 100-23, legajo 2/16, f. 87.

${ }^{160}$ Víctor Manuel Sanchis Amat, "Entre Tlatelolco y Tlatelolco: voces de la poesía mexicana en torno al 2 de Octubre de 1968", Telar 13-14 (2015): 157.

161 Tibol nació en Basavilbaso, Argentina, el 16 de diciembre de 1923. La escritora conoció a Diego
} 
Comité Mexicano de Solidaridad con el Vietnam. En el salón de actos Ruperto L. Paliza de la UAS, frente a un público de 250 asistentes, entre ellos el secretario general García Salcido, Tibol disertó la conferencia: Avances en la liberación de Vietnam. La exposición versó sobre la guerra que libraba el pueblo vietnamita "contra el imperialismo yanqui y las conciencias sufridas por la población, principalmente mujeres y niñas desvalidas"; también aludió a la ayuda humanitaria que realizaba la Cruz Roja Internacional en la que no influía la ideología. Cerró la conferencia con la proyección de un documental, donde se observaban escenas del conflicto bélico, así como vehículos entregando alimentos a la población civil. ${ }^{162}$

En otra conferencia en la Universidad, Raquel Tibol habló sobre el tema Influencias de los muralistas mexicanos, destacó los planteamientos ideológicos de Diego Rivera, David Alfaro Siqueiros, Frida Kalo y José Revueltas. Al terminar su exposición, la conferencista aprovechó el momento para vender bonos para ayudar al pueblo de Vietnam, asimismo obsequió a Liberato Terán un escudo simbólico de Vietnam, periódicos y revistas impresas en Vietnam y en Cuba con textos en español. ${ }^{163}$

En junio de 1969, en la preparatoria de la Universidad, los días viernes y sábado se llevó a cabo una conferencia, con asistencia del rector Monjaraz Buelna y 400 estudiantes y público en general. La disertación fue realizada por el Dr. Jorge Carrión (1913-2005), con el tema La crisis de la educación superior en México. Carrión, fue, junto con Manuel Marcué Pardiñas, cofundador de la revista quincenal Política, que publicó en México de mayo de 1960 a diciembre de 1967. Los temas de la revista fueron la lucha por la paz mundial, la defensa de los presos políticos, así como la Revolución cubana y la difusión de sus logros. ${ }^{164}$

Para Jorge Carrión, el auge de la educación en México se observó únicamente durante el sexenio del general Lázaro Cárdenas, ya que permitió que se educaran los hijos de los campesinos, de los obreros y del ejército. Enfatizó que existe demagogia gubernamental al sostener en la prensa que se dedica la mayor parte del presupuesto a

\footnotetext{
Rivera, en el mes de mayo de 1953, en el Congreso Continental de la Cultura (1896-1977), celebrado en Santiago de Chile. Luego se trasladó a México, invitado por Rivera para organizar el Congreso de Izquierda, pero como no se pudo organizar, entonces Tibol se dedicó al periodismo cultural. La escritora se inclinó más por los trabajos de David Alfaro Siqueiros, por encima de Rivera, ya que de él recopiló artículos, conferencias, manifiestos y diversos escritos inéditos. Raquel estuvo a cargo de la coordinación editorial de la Historia General del Arte Mexicano, y fue la responsable del volumen Época Moderna y Contemporánea (1969). Comenzó la tradición de las subastas en México para apoyar los movimientos de izquierda en Latinoamérica (El Salvador y Nicaragua. En su postura política se mantuvo fiel a su posición de izquierda. Teresa del Conde, "Raquel Tibol, 1923-2015", Anales 107 (2015): 231-234. DOI: http://dx.doi.org/10.22201/iie.18703062e.2015.107.2559; Miguel Ángel Muñoz, “Orozco y Siqueiros. La historia personal: Raquel Tibol", La Razón, 16 de noviembre de 2019. https://www.razon.com.mx/cultura/ orozco-y-siqueros-la-historia-personal-raquel-tibol/; Wikipedia, "Raquel Tibol", https://es.wikipedia.org/ wiki/Raquel_Tibol

${ }^{162}$ AGN, México, Fondo DFS, Versiones Publicas de la UAS, Caja 100-23-1, legajo 2/16, f. 246.

${ }^{163}$ AGN, México, Fondo DFS, Versiones Publicas de la UAS, Caja 100-23-1, legajo 2/16, f. 248.

${ }^{164}$ Marta Quesada, "Jorge Carrión y la revista Política”, La Jornada, (México) 10 de noviembre de 2013. https:/www.jornada.com.mx/2013/11/10/sem-marta.html?\#directora
} 
la educación; ya que afirmó que once millones de niños no asistían a ninguna escuela. Agregó que la educación en el país era para la clase media y alta, dejando la mayoría de la juventud en la injusticia social. Para solucionar el problema se necesitaba una reforma académica, burocrática y administrativa. ${ }^{165}$

Carlos Monsiváis ${ }^{166}$ en 1969, también impartió una conferencia en la escuela preparatoria de la Universidad, cuyo tema se tituló: Un mínimo de los años sesentas. Sus razonamientos se basaron en concepciones filosóficas sobre la literatura de 1960 a 1969. Monsiváis igualmente trató el tema del movimiento estudiantil del 2 de octubre, con lo cual "ha dejado impresionada a la grey estudiantil sinaloense al criticar al régimen actual que preside el Lic. Gustavo Díaz Ordaz por una sucesión de errores cometidos por sus colaboradores con relación al problema aludido. ${ }^{167}$

Durante el periodo de Liberato Terán en la dirección de la FEUS, desfilaron por la Universidad cantautores, escritores, ensayistas y politólogos de izquierda. Con eso queda demostrado que las JCM a través de la FEUS comenzó un intenso proceso de formación política hacia las bases estudiantiles. Esa postura se sostiene bajo los siguientes argumentos: Terán Olguín se había nutrido de las enseñanzas de su profesor, José Luís Ceceña Cervantes, quien desde 1966 acostumbraba organizar Semanas culturales, donde se impartían conferencias e incluso se invitaba al embajador cubano para estrechar relaciones con la Isla.

El PCM esporádicamente auspiciaba la proyección de documentales y fotografías. Por ejemplo, en agosto de 1966, el Dr. Carlos Riva Camarena, presidente de la Asociación Sinaloense Pro Amistad con China Popular Socialista, en las oficinas del FEP y la Central Campesina Independiente (CCI) exhibió 150 fotografías sobre la agresión imperialista a Vietnam. A los asistentes se les obsequiaba revistas de Vietnam y China Popular, traducidas al español, así como la revista Bohemia editada en Cuba. ${ }^{168}$ En la ciudad de México, en septiembre el Comité del Distrito Federal del PCM, acordó efectuar rondas de militantes portando carteles contra la Guerra de Vietnam, para el primero de octubre, momento cuando se inaugure el nuevo edificio de relaciones exteriores y "ver que el pueblo mexicano no quiere esa guerra". ${ }^{169}$

\footnotetext{
${ }^{165}$ AGN, México, Fondo DFS, Versiones Publicas de la UAS, legajo, Caja 100-23-1, legajo 2 /16, 22 de junio de 1969, f. 312 .

${ }^{166}$ Monsiváis, nació en 1938 en la ciudad de México, fue ensayista, cronista y narrador mexicano. Curso estudios en la Escuela Nacional de Economía y en la Facultad de Filosofía y Letras de la UNAM. Los temas tratados en sus ensayos versaban sobre los problemas actuales y comprometidos con las luchas populares de México y América Latina. Su aguda inteligencia se manifestaba a través de una eficaz ironía y de su estilo crítico, festivo y desenfadado. Sus crónicas se recopilaron en numerosos volúmenes: Principios y potestades (1969); Días de Guardar (1971), que habla de la matanza de estudiantes en la plaza de Tlatelolco el 2 de octubre de 1968. M. Ruiza, T. Fernández y E. Tamaro, "Biografía de Carlos Monsiváis", Biografías y vidas. La enciclopedia biográfica en línea (España, 2004). https://www.biografiasyvidas.com/ biografia/m/monsivais.htm

${ }^{167}$ AGN, México, Fondo DFS, Versiones Publicas de la UAS, Caja 100-23-1, legajo 2/16, f. 39.

${ }^{168}$ AGN, México, Fondo DFS, Versiones públicas de la UAS, Caja 100-23, legajo 1, fs. 230-231.

${ }^{169}$ AGN, México, Fondo DFS, Versiones públicas de la UAS, Caja 100-23, legajo 1, f. 392.
} 
A partir de 1968, la JCM, filial del PCM, desarrolló en la UAS un intenso trabajo de educación y formación política, para eso se invitaron conferencistas, escritores, se proyectaron documentales sobre la guerra de Vietnam, asimismo, por medio de aparato de sonido, se difundió la música de protesta y poesía critica. Al mismo tiempo, se formaron agrupaciones estudiantiles de poesía coral, que se presentaban en los diferentes festivales culturales organizados por la FEUS. Pero, además, el 68 trajo como consecuencia la producción de revistas, periódicos, libros, cine, teatro, radio y música, que tenía como flanco de críticas al sistema político mexicano y la cultura burguesa. ${ }^{170}$

\section{Conclusión}

Dos generaciones, dos proyectos políticos. De 1965 a 1968, confluyeron dos generaciones, una adulta y a otra joven. La primera se integró por militantes de izquierda como Monjaraz Buelna, Ceceña Cervantes y Arturo Campos Román; por otro lado figuraba García Salcido más corte liberal progresista. Los miembros de esta generación, a principios de la década de 1960, disfrutaban de espacios culturales, ${ }^{171}$ como el Ateneo Sinaloa, que tenía su centro de reunión en el Casino de la Cultura, cuyo objetivo era escuchar música, cultivar las ciencias y las letras a través de la revista Letras de Sinaloa, dirigida por Carlos Manuel Aguirre. ${ }^{172}$

La generación joven también participaba en los círculos literarios, a lados de sus profesores. Por ejemplo, estudiantes y maestros de la Normal de Sinaloa influidos por el PCM habían fundado el grupo Magisterial 18 de Abril, la inquietud era de tipo cultural, político que se inspiraba la Revolución Cubana, las huelgas ferrocarrileras y magisteriales. ${ }^{173}$ Entre los maestros fundadores, muchos de ellos se inscribieron y se graduaron en la Escuela de Economía de la UAS, entre los más destacados estaban Silvia Millán, Manuel Inzunza y Salvador Lozano Quintero; mientras que Raymundo Ríos Astorga y Arturo Campos Román siguiendo el mismo camino jugaron un papel protagónico en la Escuela de Derecho y Ciencias Sociales.

Lo cierto fue que tanto la gente de izquierda como de corte progresista liberal, abrazaron el proyecto planteado por el movimiento democratizador de Carlos Madrazo, representado en el estado por Enrique Peña Batiz. Ese proyecto político fue el que predominó en la UAS desde 1966 hasta 1968, cuyos planteamientos eran la democratización del gobierno universitario, reforma a los planes de estudio; y formar un partido de oposición al PRI con ideología de izquierda-progresista. La hegemonía

\footnotetext{
${ }^{170}$ Luis Aguilar, "Opinión pública y comunicación social en México". Setenta y cinco años de revolución IV. Educación, cultura y comunicación 2 (México, INERHRM, Fondo de Cultura Económica, 1988) 852. Citado en Héctor Jiménez Guzmán, "El 68 y sus rutas de interpretación: una crítica historiográfica” (Tesis, Maestría en historiografía de México, Universidad Autónoma Metropolitana Azcapotzalco, 2011) 117.

${ }^{171}$ Hay que aclarar que esos espacios cultuales confluían tanto intelectuales de izquierda, militantes del PCM como oficialistas. Ahí mismo asistía el rector destituido Julio Ibarra Urrea.

172 Sergio Arturo Sánchez Parra, 106-107.

${ }^{173}$ Dina Beltrán y Marco Antonio Berrelleza, Escuela Normal de Sinaloa. Una visión histórica (México: Escuela Normal de Sinaloa, 1998) 247-250.
} 
de ese proyecto fue cuestionado por el grupo Turcio Lima y el Frente Estudiantil Universitario, que pregonaban hacer propaganda con los campesinos y sectores pobres.

Con el ascenso de la JCM en la Universidad, a partir de 1968, la FEUS lanzó el proyecto de formación política de las bases estudiantiles a través de festivales culturales, donde se proyectaba documentales, se impartían conferencias de reconocidos intelectuales de izquierda, asimismo se invitaban a artistas que contaban música de protesta y los maestros organizaban grupos de teatro y poesía.

\section{Bibliografía}

\section{Fuentes primarias}

\section{Fuentes de archivo}

Archivo General de la Nación. México, Fondo Dirección Federal de Seguridad, Sección Versiones públicas de la Universidad Autónoma de Sinaloa (UAS); Fondo Investigaciones Políticas y Sociales, Caja 122-A, Exp. 1.

Archivo Histórico de la Universidad Autónoma de Sinaloa (AHUAS), Fondo Liberato Terán, Sección Actas del Consejo Estudiantil.

\section{Entrevistas}

Valenzuela Fierro, José Camilo, entrevista realizada por Rafael Santos Cenobio, Guadalajara, 15 de octubre de 2005.

Terán Olguín, Liberato Terán, entrevista realizada por Rafael Santos Cenobio, Culiacán, 15 de julio de 2004.

Millán Alarid, Alfredo Octavio, entrevista realizada por Rafael Santos Cenobio, Culiacán, 15 de julio de 2007.

\section{Fuentes secundarias}

\section{Libros}

Anónimo. Estatutos Generales y Reglamentos de Festejos de la Federación de Estudiantes Universitarios de Sinaloa. Culiacán: Universidad de Sinaloa, 1950.

Beltrán, Dina y otros. Escuela Normal de Sinaloa. Una visión histórica (México: Escuela Normal de Sinaloa, 1998.

Carr, Barry La izquierda mexicana a través del siglo XX. México: Ediciones Era, 1996. 
Enrique de la Garza, León Tomas y otros. El otro movimiento estudiantil. México: Extemporáneos México, 1986.

García S., Luis Antonio. Efemérides sinaloenses. México: Comisión Estatal de Sinaloa, 2010.

González Valdés, Ronaldo. Izquierda y Universidad: un discurso rampante (19661985). México: Colección Editorial Aldea 21 y Serie Sociedad y Pensamiento 1, 2016.

Hernández Rodríguez, Rogelio. La formación del político mexicano. El caso de Carlos A. Madrazo. México: El Colegio de México y la Universidad Autónoma de Tabasco, 1991.

Hirales Morán, Gustavo. Memoria de la guerra de los justos. México: Cal y Arena, 1996.

Hirales Morán, Gustavo. Memoria de la guerra de los justos. México: Cal y Arena, 1996.

Ibarra, María. La educación superior en México. Caracas: Centro Regional para la Educación Superior en América Latina y el Caribe, 1986.

Koselleck, Reinhart. Futuro pasado. Para una semántica de los tiempos históricos. España: Ediciones Paidós, 1993.

Laguna Berber, Mauricio. Liga comunista 23 de septiembre (LC23S). México: manuscrito, s/l y s/f.

Lozano Velásquez, Gustavo. Entre la claridad y la bruma de la educación superior en Sinaloa. México: Universidad Autónoma de Sinaloa, 1988.

Martínez Verdugo, Arnoldo. Partido Comunista Mexicano. Trayectoria y perspectivas. México: Partido Comunista Mexicano, s/f.

Martínez Verdugo, Arnoldo. Historia del comunismo en México. México: Editorial Grijalbo, 1983.

Mendoza García, Jorge. Marcos sociales, artefactos e historia. Universidad Pedagógica Nacional, México, 2015.

Ordorika, Imanol. Disputa por el Campus. Poder, política y autonomía en la UNAM. México: Universidad Autónoma de México y Plaza y Valdez, 2006.

Rosales Medrano, Miguel Ángel. Altibajos. Las UAS: vicisitudes de su desarrollo. México: Universidad Autónoma de Sinaloa, 1994. 
Santos Cenobio, Rafael. El Movimiento estudiantil en la UAS (1966-1972). México: Universidad Autónoma de Sinaloa, 2005.

Sánchez Parra, Sergio Arturo. Estudiantes en armas. Una historia política y cultural del movimiento estudiantil de los Enfermos (1972-1978). México: Universidad Autónoma de Sinaloa y Academia de Historia de Sinaloa A.C, 2012.

Terán Olguín, Liberato. Sinaloa: estudiantes en lucha. México: Universidad Autónoma de Sinaloa, 1982.

Terán Olguín, Liberato. Nueva universidad. México: Universidad Autónoma de Sinaloa, 1984.

\section{Capítulos de libros}

Aguilar, Luis. "Opinión pública y comunicación social en México”. Setenta y cinco años de revolución IV. Educación, cultura y comunicación 2. México, INERHRM, Fondo de Cultura Económica, 1988.

Archiva, Mauricio. "Entre la academia y la política: el movimiento estudiantil en Colombia, 1920-1974" en Movimientos estudiantiles en la historia de América Latina. Coord. Marsiske, Renate. México: Universidad Nacional autónoma de México, Centro de Estudios sobre la Universidad y Plaza Valdés, 1999.

Berrelleza Fonseca, Marco A. y Beltrán López, Dina. "De Liceo Rosales a Universidad Autónoma de Sinaloa (1872-1972)". La educación superior en el proceso histórico de México. Semblanzas de instituciones. tomo IV, coord. David Piñera Ramírez. México: Secretaría de Educación Púbica, Universidad Autónoma de Baja California y Asociación Nacional de Universidades e Instituciones de Educación Superior, 2002.

Beltrán López, Dina “La educación en Sinaloa en la etapa posrevolucionaria, 19451980. Segunda parte. La educación superior: la Universidad Autónoma de Sinaloa y otras instituciones", Historia temática de Sinaloa. Educación y política educativa. Coordinadores, Rosales Medrano, Miguel Ángel, Beltrán López, Dina y Sánchez Gastélum, Jorge Luis. México: Gobierno del Estado de Sinaloa, Instituto Sinaloense de Cultura y Consejo Nacional para la Cultura y las Artes.

Gómez Nashiki, Antonio. "El movimiento estudiantil mexicano. Crónica de las organizaciones y tendencias políticas, 1910-1971”. La educación superior en el proceso histórico de México. t II, Coord. Piñera Ramírez, David. México: Siglo XIX, 2001.

Halliday, Fred. "Estudiantes del mundo, uníos" en Poder estudiantil. Problemas, diagnóstico y acción, coords. Cockburn Alexander y Robin Blackburn. Caracas: Editorial Nuestro Tiempo, 1970. 
Rodríguez Gómez, Roberto. "Evolución reciente de la matrícula universitaria. Datos y reflexiones", Escenario para universidad contemporánea. Coordinadores, Muñoz García, Humberto y Rodríguez Gómez, Roberto. México: Universidad Autónoma de México, 1995.

\section{Artículos de revista}

Acevedo Tarazona, Álvaro y otros. “Cultura, política y revolución en las universidades colombianas: el arte como vanguardia del cambio social a partir de 1968”. Escripta 2 (2019): 24-44.

Barboa Cano, Fabio. “Acción y búsqueda programática”. Historia del comunismo en México. Coord. Arnoldo Martínez Verdugo. México: Editorial Grijalbo, 1983.

Braghetto G., Marco A. “1968 en México: la inesperada significación de un movimiento estudiantil de intención democrática-popular”. Escripta 2 (2019): 46-71.

Castro, Pedro. "Carlos A. Madrazo y la reforma imposible del PRI". Polis 3.1 (2007): 161-189.

Caballero Guisado, Manuela y otros, “¿Es operativo el concepto de generación?”, Aposta 56 (2013): 1-45.

Chávez Mancilla, Ángel. "De la Nicolaíta al 68. Eli de Gortari y la protesta universitaria”. Signos Históricos 19. 37 (2017): 126-155.

Del Conde, Teresa. “Raquel Tibol, 1923-2015”. Anales 107 (2015): 231-238.

Delgado, Kevyn Simón. "El 'parteaguas' a nivel local. El movimiento del 68 en la Universidad Autónoma de Querétaro”. Escripta 2 (2019): 195-216.

Escamilla Santiago, Yllich. "El movimiento estudiantil de Huanta, un eco andino del 68”, Escripta 2 (2019): 102-116.

Elena Ríos, Carmen Andrea. "Ni mártires ni bandidos. La guerrilla del GPC en Chihuahua (1963-1965”. Debates por la historia 6. 1 (2018): 13-38.

Fielbaun S., Alejandro. "Memoria, patrimonio y pos dictadura". Oralidad y memoria 1 (2009): 6-71.

Figueroa Ibarra, Carlos. "Partido, poder, masas y revolución (la izquierda en Guatemala, 1954-1996)". Cuadernos de Marte 1 (2010): 33-80.

González Mario G. "La educación superior en los sesenta: los atisbos de una transformación sin retorno", Sociológica año 23, 68 (2008): 15-39. 
Ghiardo, Felipe. "Generaciones y juventud: una relectura desde Mannheim y Ortega y Gasset”. Última década 20 (2004): 11-46.

Lozano González, Elí Orlando. "Los ritmos de la rebeldía: la música en la formación política de estudiantes activistas universitarios". Revista de Ciencias Políticas y Sociales 237 (2019): 65-94.

Meyer, Lorenzo. "La prolongada transición mexicana: ¿del autoritarismo hacia dónde? Revista de Estudios Políticos 74 (1991): 363-387.

Moreno Elizondo, J. Rodrigo. "El movimiento estudiantil-popular de 1968 y la recomposición de las organizaciones políticas de izquierda". Revista Mexicana de Ciencias Políticas y Sociales 234 (2018): 239-264.

Moreno González, María Guadalupe. “La izquierda y los movimientos sociales: el caso del Partido Comunista en Jalisco y la guerra sucia en Guadalajara de los años setenta". R.H.A 142 (2010): 9-23.

Meyer, Jean. "El movimiento estudiantil en América Latina", Sociológica 23, 68 (2008):179-195.

Mignolo, Walter D. "Democracia liberal, camino de la autoridad humana y transición al vivir bien”. Sociedad e Estado 29. 1 (2014): 21-44.

Paredes, Juan Pablo y otros, "Conflicto social y subjetividad política: performance, milicias y memoria en la movilización estudiantil post 2011", Persona y sociedad 2 (2018): 122-149.

Puma Crespo, Jorge Iván. "Los maoístas del norte de México: breve historia de Política Popular-Línea Proletaria, 1969-1979”. Revista izquierdas 27 (2016): 200-229.

Pozas-Horcasitas, Ricardo. "La democracia fallida: la batalla de Carlos A. Madrazo por cambiar al PRI”. Revista Mexicana de Sociología 70.1 (2008): 47-85.

Quintero Timaná, Diego Andrés y otros. "La configuración del campo intelectual contestatario: Universidad de Nariño (1960-1970)". Anuario de Historia Regional $y$ de las Fronteras 2 (2020), 187-217.

Rama Vitale, Claudio. "La tercera reforma de la educación superior en América Latina y el Caribe: masificación, regulaciones e internacionalización", Educación y pedagogía 28, 46 (2006): 11-24.

Santos Cenobio, Rafael. "Discursos, símbolos e iconos de la disidencia: del movimiento estudiantil a la radicalidad en Sinaloa, México, 1966-1973". Conjeturas Sociológicas 14 (2017): 10-37. 
Sanchis Amat, Víctor Manuel. "Entre Tlatelolco y Tlatelolco: voces de la poesía mexicana en torno al 2 de Octubre de 1968". Telar 13-14 (2015): 150-165.

Suasnábar, Claudio. "Los ciclos de reforma educativa en América Latina: 1960, 1990 y 2000. Revista española de educación comparada 30 (2017): 112-135.

Serrano Álvarez, Pablo. "Tendencias y enfoques metodológicos, 1968-1990". Relaciones 72 (1997): 49-57.

Terán. Lorenzo Q. Tribuna impresa. Crónica periodística, 1966-1970. México: Universidad Autónoma de Sinaloa, 2004.

Tirado Villegas, Gloria A. y otros. "A cuarenta años del movimiento estudiantil. Universitarias de los años setenta en la Universidad Autónoma de Puebla, México". Cuadernos Intercambio sobre Centroamérica y el Caribe 1 (2014): 27-44.

Tirado Villegas, Gloria Armida. "Puebla 1961, género y movimiento estudiantil”. La ventana 39 (2014): 179-207.

Vázquez Mendeles, Juan Carlos. "El olvido en la memoria de Rogelia Cruz Martínez". Tzintzun 56 (2012): 169-210.

\section{Tesis, ponencias y otros}

Castillo Farjat, Lizbeth. "La oposición revolucionaria en el proceso electoral" de 1952-1954). Tesis inédita de Maestría en Historia, El Colegio de San Luis, 2009.

Cejudo Ramos, Denisse de Jesús. "La Universidad en el naufragio: contienda política en la Universidad de Sonora, 1991". Tesis inédito de Doctorado en Historia Moderna y Contemporánea, Instituto de Investigaciones Dr. José María Luis Mora, 2016.

Galaviz Miranda, Cuitláhuac Alfonso. "Las dimensión simbólica de la protesta: el caso de las movilizaciones estudiantiles de 1970-1973 en la Universidad de Sonora". Tesis inédita de Maestría en sociología política, Instituto de Investigaciones Dr. José María Luis Mora, 2016.

Galaviz Hernández, Beatriz. “'En primavera florecen los murales'. El arte activista en el movimiento estudiantil de la Universidad de Sonora, 1991-1992. Prácticas y estrategias". Tesis inédita de Maestría en Ciencias Sociales, Universidad de Sonora, 2016.

Jiménez Guzmán, Héctor. "El 68 y sus rutas de interpretación: una crítica historiográfica". Tesis inédita de Maestría en historiografía de México, Universidad Autónoma Metropolitana Azcapotzalco, 2011. 
Ramírez Hernández, Miguel Ángel. "La ideología y la institucionalización de la identidad política. El caso del Partido Revolucionario Institucional (1929-2017)”. Tesis inédita de Maestría en Asuntos Políticos y Políticas Públicas, El Colegio de San Luis, 2018.

Ramírez Hernández, Miguel Ángel. "La ideología y la institucionalización de la identidad política. El caso del Partido Revolucionario Institucional (1929-2017)”. Tesis inédita de Maestría en Asuntos Políticos y Políticas Públicas, El Colegio de San Luis, 2018.

Simón Delgado, Kevyn. "El Partido Comunista Mexicano y el movimiento estudiantil de 1968: enfrentamiento, aportación e impacto". Tesis inédita de Licenciatura en Historia, Universidad Autónoma de Querétaro, 2013.

\section{Prensa}

Crónica10 (Cajeme) 2016.

Diario de Culiacán, Culiacán, 1966.

La Jornada (Acapulco), 2018.

La Razón (México) 2019.

La Jornada, (México) 2013.

Noroeste, Culiacán, 2016.

\section{Publicaciones en internet}

M. Ruiza, T. Fernández y E. Tamaro, "Biografía de Carlos Monsiváis”, Biografías y vidas. La enciclopedia biográfica en línea (España, 2004). https://www. biografiasyvidas.com/biografia/m/monsivais.htm

Wikipedia, "Eduardo Valle 'El Búho”, 26 de julio de 2020. https:/es.wikipedia.org/ wiki/Eduardo_Valle_\%22El_B\%C3\%BAho\%22

Torres Escobar, A. G. "Margarita Bauche: Libertad, justicia, amor, canción de protesta", 27 de abril de 2014. http://blancaauroramondragon.blogspot.com/2014/04/ nocturno-rosa-margarita-bauche-y-hugo.html

Wikipedia, “Raquel Tibol”, https://es.wikipedia.org/wiki/Raquel_Tibol 